\title{
LA GUERRA CONTRA EL NARCOTRÁFICO EN MEXICO, ¿UN CONFLICTO ARMADO NO INTERNACIONAL NO RECONOCIDO? 1
}

\author{
THE WAR ON DRUGS IN MEXICO: AN UNRECOGNIZED \\ NON-INTERNATIONAL ARMED CONFLICT?
}

\section{LA GUERRE CONTRE LE TRAFIC DE DROGUES AU MEXIQUE, CONFLIT ARMÉ NON INTERNATIONAL ET NON RECONNU?}

\author{
Ana Gabriela Rojo Fierro \\ University of Amsterdam \\ anagabrielarojo@gmail.com
}

\begin{abstract}
RESUMEN: Este trabajo es una reflexión en torno a la clasificación jurídica de la llamada "guerra contra el narcotráfico" en México a la luz del derecho internacional humanitario (DIH), que regula la conducción de los conflictos armados, tanto internacionales como no internacionales. Después de un recuento de las particularidades de este conflicto, se argumenta la pertinencia jurídica de reconocer la situación mexicana como un "conflicto armado no internacional” y exigir la consecuente aplicación del DIH.

Palabras clave: derecho internacional humanitario (DIH); conflicto armado no internacional (CANI); guerra contra el narcotráfico; crimen organizado; México
\end{abstract}

AвSTRACT: This paper reflects on the legal classification of the "war on drugs" in Mexico from the perspective of international humanitarian law, which regulates international and non-international armed conflicts. Following an overview of different aspects of this conflict, I discuss the legal feasibility of acknowledging the ongoing violence in Mexico as a "non-international armed

${ }^{1}$ Este trabajo se deriva de una investigación desarrollada en el marco de la tesis de licenciatura, titulada "El punto ciego de la justicia: la guerra contra el narcotráfico y el derecho internacional humanitario", defendida el 7 de diciembre 2017 en la Universidad Iberoamericana de León. 
conflict" (CANI in Spanish), and demanding the corresponding measures of International Humanitarian Law.

Key words: international humanitarian law; non-international armed conflict; war on drugs; organized crime; Mexico.

\section{Traducción de Gonzalo Celorio Morayta}

RÉsumé: Ce travail constitue une réflexion sur la qualification légale de la dite «guerre contre le trafic de drogues» au Mexique, au regard du droit international humanitaire (DIH), lequel encadre la manière avec laquelle les conflits armés sont menés, qu'ils soient internationaux ou non. Après un examen des caractéristiques propres à ce conflit, l'article évalue s'il serait juridiquement pertinent de qualifier la situation mexicaine de conflit armé non international, et ainsi d'exiger une application du DIH.

Mots clés: droit international humanitaire (DIH); conflit armé non international (CANI); guerre contre le trafic de drogues; crime organisé; Mexique.

\section{Traducción de ARIEL ElBAZ}

Fecha de recepción: abril de 2019

Fecha de aceptación: julio de 2020 


\section{INTRODUCCIÓN}

Si no se establecen limitaciones éticas ni legales a la decisión de iniciar una guerra (ius ad bellum) y a la manera de conducirla (ius in bello), ésta no es más que el uso de la fuerza bruta; no se distingue, por lógica, de la matanza masiva.

A.J. Bellamy, Guerras justas: de Cicerón a Iraq ${ }^{2}$

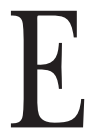
n la historia de la humanidad, no son escasos los intentos de regular la conducción de la guerra, de distinguirla de una "matanza masiva", como diría Bellamy. ${ }^{3}$ Siguiendo a este autor, en la civilización azteca, por ejemplo, se libraban batallas con número de contendientes, días y lugares previamente acordados; en China, Sun Tzu, estratega del siglo v, enfatizaba la necesidad de que los ejércitos tratasen respetuosamente a los prisioneros y a los no combatientes; igualmente, en la antigua Grecia existían restricciones no sólo para la conducción de la guerra, sino para la decisión de iniciarla; y el Imperio romano, mediante el ius gentium, reconocía restricciones universales a la conducta de guerra.

En este sentido, el paso del tiempo ha visto no sólo formas más modernas de hacer la guerra, sino de regularla. Entre los instrumentos contemporáneos más relevantes para identificar, regular y sancionar las cuestiones de la guerra se encuentra el derecho internacional humanitario (DIH o ius in bello), el cual limita jurídicamente la forma en que se conduce. Entre otras, tales restricciones se refieren al tipo de armas empleadas, a los objetivos militares que pueden atacarse y a la forma de realizar tales ataques. Adicionalmente, el DIH

2 A.J. Bellamy, Guerras justas: de Cicerón a Iraq, Madrid, Fondo de Cultura Económica, 2009, p. 21.

${ }^{3}$ Loc. cit. 
responsabiliza jurídica e internacionalmente a los combatientes respecto de su actuación en el conflicto.

Dado que no todo escenario de violencia supone una guerra, de tal distinción depende la aplicación del cuerpo jurídico del DIH. En la práctica, la identificación de conflictos armados de carácter internacional comporta menos dificultades que la de conflictos internos, ya que invasiones u ocupaciones extranjeras los distinguen con facilidad, mientras que es más difícil discernir si la violencia interna de un país ha alcanzado los parámetros de una guerra. ${ }^{4}$ Adicionalmente, mientras que un Estado puede considerar beneficioso denunciar y regular un conflicto internacional, otra cosa sucede con los conflictos internos. En ellos se tiende a favorecer discursos que minimizan la violencia, dado que la aplicación del DIH limita las medidas represivas a las que el Estado puede recurrir, genera un mayor escrutinio a nivel internacional y los considera sujetos de sanción en caso de incumplimiento. ${ }^{5}$

A estos retos en la identificación de conflictos internos, podemos añadir la dificultad derivada de la transformación de los conflictos bélicos. Bajo el concepto de "nuevas guerras"6

${ }^{4}$ S. Vité, "Tipología de los conflictos armados en el derecho internacional humanitario: conceptos jurídicos y situaciones reales", International Review of the Red Cross, núm. 873, marzo de 2009; E. Salmón, Introducción al Derecho Internacional Humanitario, Lima, Instituto de Democracia y Derechos Humanos Pontificia Universidad Católica del Perú, 2004; J.J. Ferro, "Existencia de un conflicto armado interno: ¿quién decide?, Revista de Derecho Público (2011), pp. 1-31.

${ }^{5}$ Ferro, art. cit.

${ }^{6}$ Z. Bauman, "Wars of the Globalisation Era", European Journal of Social Theory, 4(1), (2001): 11-28, en S. Malešević, The sociology of war and violence, Cambridge, University Press, 2010. Z. Bauman, "Society under Siege”, Cambridge, Polity Press, 2002, en S. Malešević, The sociology of war and violence, Cambridge, University Press, 2010. M. Shaw, "Risk-Transfer Militarism, Small Massacres and the Historic Legitimacy of War. International Relations", 17(3) (2002), pp. 343-60, en Malešević, S., The sociology of war and violence, Cambridge, University Press, 2010. M. Kaldor, "New and Old Wars: Organised Violence in a Global Era", Cambridge, Polity Press, 2001, en Malešević, S., The sociology of war and violence, Cambridge, University Press, 2010. 
se argumenta la existencia de diferencias profundas en las guerras contemporáneas en cuanto a métodos, estrategias, tácticas y objetivos, argumentando que esta transformación se relaciona con procesos de globalización económica, donde los conflictos bélicos actuales son predominantemente instrumentales, en lugar de ideológicos o nacionalistas. $^{7}$

En este sentido, la violencia relacionada con el crimen organizado y el narcotráfico pareciera tener más en común con este tipo de guerras que con aquellas que motivaron el surgimiento y desarrollo de importantes instrumentos del DIH -siglo XIX y Xx, principalmente-. Las guerras civiles económicas, como las nombraría Schedler, ${ }^{8}$ se gestan en colusión con las autoridades, con enemigos y aliados difusos y transitorios. Y a pesar de que el DIH no debe regular en función de la motivación de los combatientes, sean políticas o de carácter económico, sus distintos criterios están pensados en función de las modalidades en que operan agentes con intereses políticos. Del mismo modo, en el debate internacional, este tipo de violencia -o posibles guerras- no ha sido discutida con la misma urgencia con que se tratan situaciones relacionadas con el terrorismo o con movimientos armados con demandas políticas.

Como consecuencia de ello, si bien son loables los esfuerzos por responsabilizar a los Estados en cuanto a su actuación en conflictos armados, pareciera ser que el marco jurídico del DIH actual implica una suerte de desamparo jurídico respecto a las problemáticas relacionadas con el narcotráfico y otras relacionadas con el crimen organizado.

Achille Mbembe, en referencia a la época colonial en África, afirma lo siguiente:

${ }^{7}$ M. Shaw, "War and Genocide: Organized Killing in Modern Society", Cambridge, Polity Press, 2003, p. 71, en S. Malešević, The sociology of war and violence, Cambridge, University Press, 2010, p. 318.

${ }^{8}$ A. Schedler, En la niebla de la guerra: Los ciudadanos ante la violencia criminal organizada, México, cIDE, 2015. 
Este periodo constituye una manifestación de no-reconocimiento como Estado y mundo humano y, por tanto, como lugar en el que los colonizadores imaginan imposible acordar la paz, donde incluso resulta impertinente hacer una distinción entre guerra y paz. ${ }^{9}$

Esta reflexión, en pleno siglo xxi y en nuestra región, pareciera ser vigente. En el mundo bárbaro de América Latina parece no valer la pena distinguir entre la guerra y la paz. Además de enfrentarnos a la violencia, nos enfrentamos a la renuencia a reconocer -e incluso preguntarse- si nuestras guerras, aparentemente invisibles, pudieran constituir conflictos armados.

El caso de México parece ilustrar esta situación, al ser un país que lleva más de una década asediado por actos que han derivado en un contexto de violencia generalizada, acompañado de una militarización del país que dio inicio en 2006, la cual se argumentó como estrategia de seguridad pública más que de carácter bélico. En la práctica, sin embargo, el escenario rebasa cualquier explicación de lucha contra el crimen, narrativa que resulta insuficiente para describir el desgarramiento de un país con más de 200000 muertos, 60000 desaparecidos, e incontables fosas clandestinas.

Derivado de esta situación de invisibilidad jurídica se plantea el objetivo del presente artículo: analizar la viabilidad de encuadrar el conflicto mexicano, la así llamada "guerra contra las drogas", como un conflicto armado no internacional, y analizar las implicaciones jurídicas que esto conllevaría.

Con este propósito, en este trabajo realizamos una comparación de los instrumentos jurídicos relevantes del DIH con información y datos empíricos de la situación mexicana. Para ello, presentamos en primer término un recuento somero del propósito del DIH, los tipos de conflicto armado según la legislación internacional y las principales definicio-

${ }^{9}$ F. B. González, "Necropolítica, de Achille Mbembe”, Clivajes. Revista de Ciencias Sociales, (4), 150, 2015. 
nes de los tratados internacionales (Convenios de Ginebra, Protocolo Adicional II, Estatuto de Roma y jurisprudencia Tadic v. Prosecutor). Posteriormente, se contrastan los elementos contemplados por las definiciones con el escenario en México, utilizando datos empíricos que contemplan información gubernamental y datos periodísticos, entre otros.

El resultado de dicho análisis nos lleva a sostener que la guerra contra el narcotráfico en México puede considerarse como un conflicto armado no internacional de acuerdo con tres de los cuatro instrumentos jurídicos analizados. Finalmente abordamos las implicaciones derivadas de dicha clasificación, señalando a su vez algunos temas pendientes para el país en cuanto a su estrategia de seguridad.

\section{ANTECEDENTES Y CONTEXTO DE LA DISCUSIÓN}

Si bien hay un uso frecuente del término 'guerra' para referirse a la lucha del Estado mexicano contra el crimen organizado, desde la perspectiva jurídica poco se ha dicho sobre si efectivamente se trata de un escenario bélico. ${ }^{10}$

Siguiendo el curso de las discusiones, es posible identificar tres distintas posturas sobre la naturaleza del conflicto en México. La primera, que incluye las voces de defensores de derechos humanos, organizaciones de la sociedad civil y politólogos, sostiene que sí nos encontramos ante un escenario bélico. Su argumento principal se basa en las estadísticas sobre homicidios y desaparecidos, que presentan una situación alarmante, así como la prolongación del conflicto en el tiem-

${ }^{10}$ E. Arratia, “¿Existe un conflicto armado interno en México según el derecho internacional? Los Convenios de Ginebra y su aplicación en la guerra contra el narcotráfico (2006-2012)", Revista de Estudios en Seguridad Internacional, 2015; H. Carreón y E. Téllez, “¿Existe un conflicto armado interno en México? Análisis a la luz del Derecho Penal Internacional", Lex 2 (10), 2012, pp. 15-42. 
po. ${ }^{11}$ Igualmente, en alusión al concepto de 'guerra civil' -de carácter político, no jurídico- se refieren a que los conflictos con más de 1000 muertes al año se catalogan, tradicionalmente, como guerra civil, y dado que México supera con mucho este número, puede considerarse como tal. ${ }^{12}$

Una segunda postura es la de estudiosos del derecho internacional en Bélgica, México y Chile, quienes han asegurado que a pesar de la gravedad de la violencia en México, jurídicamente no hay suficientes argumentos para sostener que se trate de un conflicto armado. ${ }^{13}$

Una tercera postura está representada por numerosos organismos internacionales, y la denominaremos inespecífica, ya que si bien denuncian la violencia que vive el país, han tendido a permanecer en silencio respecto a su posible categoría jurídica, lo que constituye de facto una negación, por omisión, de su reconocimiento como un conflicto armado.

En el contexto del debate público, hay dos situaciones distintas que han puesto de relieve esta discusión. La primera surge en 2011, cuando el abogado mexicano Netzaí Sandoval presenta ante la Corte Penal Internacional una denuncia contra el entonces presidente Felipe Calderón y gran parte de su gabinete, acusándolos de haber cometido crímenes de lesa humanidad. ${ }^{14}$ Esto dio lugar a un tema de debate, dado que la viabilidad de la demanda dependía de que se reconociera la existencia de una guerra en México. ${ }^{15}$

${ }^{11}$ C. E. Cruz Santiago, México la guerra invisible. Historias, cifras y negocios de los carteles criminales y la impunidad de las mafias mexicanas, México, Libera, 2012; G. Santamaría, "Violencia sin justicia en México: la guerra y sus consecuencias", Open Democracy, 2016.

12 Schedler, op. cit; R. Jaimez y P. Díaz, "Nuevas claves para pensar la violencia en México, más allá del narcocentrismo. Caso Guerrero y su guerra sin fin”, Horizontal, 2017.

${ }^{13}$ M. Appel, "Ante el Estado fallido, narcoestado sustituto", Proceso, 8 de mayo de 2012; Carreón y Téllez, art. cit.; Arratia, art. cit.

${ }^{14}$ G. Díaz, "Demanda contra Calderón en La Haya, el 25 de noviembre”, Proceso, 2011.

${ }^{15}$ El Tribunal Especial para la Antigua Yugoslavia considera que los crímenes de lesa humanidad deben cometerse en el contexto de un con- 
Años después, en 2017, el debate reaparece cuando el International Institute for Strategic Studies (IISs) emite un informe en el que no sólo afirma que México se encuentra en medio de un escenario bélico, sino que lo ubica como el segundo conflicto armado más violento del mundo, sólo después de la guerra civil en Siria. ${ }^{16}$

En respuesta a dicho informe, el gobierno mexicano emitió un comunicado a través de la cancillería, el cual además de refutar con fundamento las incongruencias metodológicas y las estadísticas empleadas, afirmó que no existía un conflicto armado en México, argumentando que "La existencia de grupos criminales no es un criterio suficiente para hablar de un conflicto armado no internacional. Tampoco lo es el uso de las Fuerzas Armadas para mantener el orden al interior del país". ${ }^{17}$

A continuación, señaló que, más que un conflicto armado no internacional, se trataba de un fenómeno criminal y regional. De esta forma, el gobierno mexicano rechazaba la existencia de un escenario bélico, reduciendo la violencia a una lucha contra el crimen.

Sin embargo -y como se verá más adelante- ni el carácter transnacional de las organizaciones criminales, ni la ausencia de demandas políticas eliminan la posibilidad de que exista una guerra en México. Y si bien es cierto que, derivado de modificaciones constitucionales, el ejército mexicano ha recibido facultades que prolongan su permanencia en tareas

flicto armado, mientras que el Tribunal Especial para Ruanda no lo exige como tal, M.C. Roberge, "Jurisdicción de los Tribunales ad-hoc para ex Yugoslavia y Ruanda...”, 1997. Por ello, determinar si en México hay un conflicto armado es relevante en la procedencia de la demanda contra Calderón por crímenes de lesa humanidad.

${ }^{16}$ International Institute for Strategic Studies, IIss, Armed Conflict Survey, IIss, Londres, Routledge, International Institute for Strategic Studies, 2017.

17 Secretaría de Gobernación, Segob, "El reporte 'Armed Conflict Survey 2017' (ACS), publicado por el International Institute for Strategic Studies (IISs)", comunicado de prensa, México, 10 de mayo de 2017. 
de seguridad, ${ }^{18}$ esto tampoco descarta que exista un conflicto armado no internacional. Incluso, siguiendo a Saint-Pierre y Donadelli, ${ }^{19}$ ésta pareciera ser parte de una tendencia en América Latina en la que se desdibujan los límites entre guerra y crimen, entre lo militar y lo policial.

En este sentido, el Estado puede, por un lado, desplegar unidades militares a lo largo y ancho de su territorio -como si estuviese en un conflicto armado- y, por el otro, decidir no aplicar medidas del derecho internacional humanitario (DIH) argumentando que no se trata verdaderamente de una guerra, sino de una lucha contra el crimen. Esta situación de ambigüedad es la que este artículo se propone explorar en su dimensión jurídica.

Una vez identificadas estas tres posturas sobre el tema, a continuación, abordaremos el propósito y marco jurídico del DIH, así como los elementos que se necesitan para determinar la tipificación o no del caso mexicano como un conflicto armado.

\section{Derecho InTERnacional Humanitario y EL RETO De LOS CONFLICTOS ARMADOS NO INTERNACIONALES (CANI)}

Para analizar la posible tipificación de la guerra contra el narcotráfico en México como un conflicto armado no internacional, en este apartado abordamos el DiH, que regula los conflictos bélicos. En primer término referimos la naturaleza y propósito del DIH, así como las dos categorías de conflicto armado contempladas en esta legislación -conflictos armados internacionales y no internacionales-. Posteriormente se destacan las dificultades que supone la identificación de

${ }^{18}$ M. Serrano, "La estrategia de seguridad de AmLo. ¿De la pacificación a la militarización?”, Revista IUS, 13 (44), 2019, pp. 207-228.

${ }^{19}$ H. L. Saint-Pierre y L. M. Donadelli, "El empleo de las fuerzas armadas en asuntos internos", en G. Maihold y S. Jost (eds.), El narcotráfico y su combate. Sus efectos sobre las relaciones internacionales, México, Konrad Adenauer Stifung, 2014, pp. 59-74. 
los conflictos armados no internacionales y, finalmente se presenta un esquema comparativo de las principales definiciones de conflicto armado no internacional en tratados internacionales, con el propósito de identificar los elementos jurídicos relevantes para determinar si el caso mexicano puede considerarse un conflicto armado no internacional.

\section{Ius ad bellum $e$ ius in bello}

Como es sabido, el derecho internacional en general prohíbe la guerra, excepto en situaciones de legítima defensa frente a un ataque armado o cuando el Consejo de Seguridad de la Organización de Naciones Unidas (onU) decide su uso frente a una amenaza, quebrantamiento de la paz o acto de agresión..$^{20}$ Por su parte, el DIH implica un conjunto de normas, de origen convencional o consuetudinario, para atender los problemas humanitarios derivados de los conflictos armados. Desprovisto de cualquier papel legitimador, no corresponde al derecho humanitario determinar las situaciones en las que resulta válido el recurso a la fuerza armada (ius ad bellum), sino la forma en que puede conducirse la guerra (ius in bello). ${ }^{21}$

En este sentido, el DIH afirma que la persona nunca pierde su dignidad intrínseca, trátese de un civil o de un miembro de las fuerzas armadas. Su propósito es establecer un equilibrio entre aquello que es necesario para vencer al adversario y lo que denota crueldad. Las infracciones graves del DIH en conflictos armados constituyen crímenes de guerra, y los presuntos criminales son susceptibles de ser enjuiciados por la Corte Penal Internacional. ${ }^{22}$

${ }^{20}$ Capítulo VII de la Carta de las Naciones Unidas (artículo $2^{\circ}$, inciso 4 de la Carta de las Naciones Unidas), Carta de las Naciones Unidas, 1945.

${ }^{21}$ Salmón, op. cit.

${ }^{22}$ K. Lawand, "Conflictos internos u otras situaciones de violencia: ¿cuál es la diferencia para las víctimas?”, Ginebra, Comité Internacional de la Cruz Roja, 10 de diciembre de 2012. 
El derecho internacional humanitario se aplica a situaciones -los conflictos armados- que no deberían existir si el derecho fuese respetado. [...] Contexto difícil e indeseable, por tanto, aquel en el que el derecho internacional humanitario está llamado a actuar. Su objetivo principal, garantizar un mínimo de humanidad en una situación inhumana, no lo es menos. ${ }^{23}$

El DIH no es aplicable a todas las situaciones de violencia generalizada, sino únicamente a casos de guerra. De acuerdo con la jurisdicción internacional, existen sólo dos tipos de conflicto bélico: el conflicto armado internacional y el conflicto armado no internacional. Los primeros serán aquellos en que se enfrentan dos o más Estados, o los casos de ocupación total o parcial del territorio de una alta parte contratante, inclusive si tal ocupación no encuentra resistencia militar. Por su parte, se entenderán los conflictos armados no internacionales como aquellos entre fuerzas gubernamentales y grupos armados no gubernamentales. ${ }^{24}$

Tradicionalmente, los conflictos armados considerados por el derecho eran los de carácter interestatal, ya que la relación entre un Estado y su propia ciudadanía se consideraba un asunto de la constitución y de las leyes internas. La situación de conflicto armado no internacional (CANI) fue contemplada por primera vez en los Convenios de Ginebra de 1949 , en el artículo $3^{\circ}$ común a los cuatro convenios, cuyas reglas mínimas constituyeron su primer régimen internacional. ${ }^{25}$ Veintiocho años después, con la adopción en 1977

${ }^{23}$ Salmón, op. cit.

24 Comité Internacional de la Cruz Roja, CICR, "El derecho internacional humanitario y los desafíos de los conflictos armados contemporáneos", XXXI Conferencia Internacional de la Cruz Roja y de la Media Luna Roja, Ginebra, 2011: 4.

${ }^{25}$ C. S. Swinarski, "Derecho internacional humanitario como sistema de protección de la persona humana en su relación con el derecho internacional de los derechos humanos", en S. Fraidenraij y R. Méndez Silva (eds.), Elementos de derecho internacional humanitario, México, unAM, Instituto de Investigaciones Jurídicas, 2001. 
del Protocolo Adicional II, este tipo de conflictos incorpora mayor regulación en un cuerpo normativo cuyo propósito fundamental es la protección de las víctimas.

Sin embargo, como se ha mencionado, a pesar de los esfuerzos jurídicos, la delimitación de las situaciones tipificables como cANI ha supuesto más retos que su contraparte internacional:

Como se sabe, el régimen jurídico aplicable a estas situaciones es mucho más limitado que el que concierne a los conflictos armados internacionales. El derecho internacional humanitario sólo define estas situaciones en términos negativos: "no internacionales" (artículo 3o.) y "no cubiertos por..." (Protocolo adicional II) como si hubiera una reticencia en nombrar algo que realmente no se quiere nombrar, porque nombrar es reconocer. ${ }^{26}$

Como se señaló, en la práctica tanto jurídica como política, el reconocimiento de conflictos armados internos supone más dificultades que la de los internacionales. Adicionalmente, hay mayor resistencia del propio Estado para reconocer un CANI, debido a los límites que impone a su conducta respecto a los combatientes, además de que este reconocimiento pondría en tela de juicio su capacidad de gobernabilidad, atentaría contra el prestigio del Estado en la comunidad internacional y afectaría la confianza inversionista. En este sentido, no sólo las partes combatientes pueden denunciar la existencia de un CANI, sino que la comunidad internacional, los organismos internacionales y el CICR pueden favorecer su identificación como tal. ${ }^{27}$

Considerando la renuencia de los propios países para reconocer la existencia un CANI, que podría ser el caso del go-

${ }^{26}$ R. Hammer, "Cincuenta años de aplicación de los Convenios de Ginebra”, en S. Fraidenraijy R. Méndez Silva (eds.), Elementos de derecho internacional humanitario, México, UNAM, Instituto de Investigaciones Jurídicas, 2001.

${ }^{27}$ D. P. Henao, "La lucha armada contra el narcotráfico en Colombia y México: un análisis a la luz del artículo 3 común a los Convenios de Ginebra”, Estudios en Seguridad y Defensa, 8 (16), 2013, pp. 47-58. 
bierno mexicano, es necesario analizar directamente las fuentes jurídicas que permiten dilucidar la existencia o no de un escenario bélico.

Hay diversas definiciones sobre lo que constituye un conflicto armado, todas ellas válidas en derecho internacional pero que invocan distintas obligaciones para los Estados. Ferro $^{28}$ propone un análisis sobre la evolución de la categoría jurídica de CANI, destacando que las definiciones más importantes en esta materia se encuentran en el artículo $3^{\circ}$ de los Convenios de Ginebra, el artículo $1^{\circ}$ del Protocolo Adicional II de los Convenios de Ginebra, el artículo $8^{\circ}$ del Estatuto de Roma y la decisión jurisprudencial del Tribunal Especial para la Antigua Yugoslavia en el caso Tadic v. Prosecutor.

Estas definiciones se encuentran en los principales instrumentos del DIH -los Convenios de Ginebra-y en el documento base de la Corte Penal Internacional, el Estatuto de Roma. Por su parte, la jurisprudencia del caso Tadic se considera una de las más relevantes respecto a la existencia de un conflicto armado interno, ya que su interpretación del artículo $3^{\circ}$ ha sido sumamente influyente en codificaciones posteriores. ${ }^{29}$

Cabe señalar que la aplicabilidad o no de un instrumento no repercute en la de los demás; es decir, en un conflicto puede ser aplicable el artículo $3^{\circ}$ común de los Convenios de Ginebra y a la vez inaplicable el Protocolo Adicional II, debido a sus estándares más estrictos. ${ }^{30}$ Por lo tanto, estos instrumentos deben analizarse individualmente para verificar si el caso estudiado cumple con las características requeridas.

El siguiente cuadro sintetiza los requisitos de estos instrumentos para la tipificación de un escenario de violencia como conflicto armado no internacional.

${ }^{28}$ Ferro, art. cit.

${ }^{29}$ Loc. cit.

${ }^{30}$ Inclusive, como parte de una crítica a los estándares más estrictos del Protocolo Adicional II, Ferro, art. cit., señala que el genocidio en Ruanda podría no ser considerado un CANI siguiendo este instrumento, y que entonces sólo serían aplicables las protecciones del artículo $3^{\circ}$ común de los Convenios de Ginebra. 


\section{Cuadro 1 \\ Requisitos para la tipificación de escenarios de violencia en instrumentos internacionales}

\begin{tabular}{|c|c|c|c|c|}
\hline Definición & Articulo $3^{\circ}$ & PA II & Estatuto de Roma & Caso Tadic \\
\hline $\begin{array}{l}\text { Actores } \\
\text { involucrados }\end{array}$ & $\begin{array}{c}\text { No requiere la } \\
\text { participación de las } \\
\text { fuerzas armadas } \\
\text { del Estado. Es } \\
\text { aplicable en } \\
\text { conflictos entre } \\
\text { grupos armados }\end{array}$ & $\begin{array}{c}\text { Se desarrolla entre } \\
\text { fuerzas armadas y } \\
\text { fuerzas armadas } \\
\text { disidentes o grupos } \\
\text { armados } \\
\text { organizados }\end{array}$ & $\begin{array}{l}\text { No requiere la } \\
\text { participación de las } \\
\text { fuerzas armadas } \\
\text { del Estado. Es } \\
\text { aplicable en } \\
\text { conflictos entre } \\
\text { grupos armados }\end{array}$ & $\begin{array}{l}\text { No requiere la } \\
\text { participación de las } \\
\text { fuerzas armadas } \\
\text { del Estado. Es } \\
\text { aplicable en } \\
\text { conflictos entre } \\
\text { grupos armados }\end{array}$ \\
\hline $\begin{array}{l}\text { Intensidad del } \\
\text { conflicto }\end{array}$ & $\begin{array}{c}\text { Nivel de violencia } \\
\text { propio de un } \\
\text { conflicto armado }\end{array}$ & $\begin{array}{c}\text { Nivel de violencia } \\
\text { propio de un } \\
\text { conflicto armado }\end{array}$ & $\begin{array}{l}\text { Nivel de violencia } \\
\text { propio de un } \\
\text { conflicto armado }\end{array}$ & $\begin{array}{l}\text { Nivel de violencia } \\
\text { propio de un } \\
\text { conflicto armado }\end{array}$ \\
\hline $\begin{array}{l}\text { Organización } \\
\text { de los grupos }\end{array}$ & No lo establece & $\begin{array}{c}\text { Deben estar } \\
\text { organizados bajo la } \\
\text { dirección de un } \\
\text { mando responsable } \\
\text { que pueda dirigir } \\
\text { ataques }\end{array}$ & $\begin{array}{l}\text { Tienen que ser } \\
\text { grupos armados } \\
\text { organizados }\end{array}$ & $\begin{array}{c}\text { Deben ser } \\
\text { organizaciones } \\
\text { armadas }\end{array}$ \\
\hline Control territorial & No lo establece & $\begin{array}{c}\text { Deben ejercer } \\
\text { sobre una parte del } \\
\text { territorio un } \\
\text { control tal..." }\end{array}$ & No lo establece & No lo establece \\
\hline \begin{tabular}{|c|} 
Operaciones \\
militares sostenidas \\
y concertadas
\end{tabular} & No lo establece & $\begin{array}{c}\text { “... que les permita } \\
\text { realizar } \\
\text { operaciones } \\
\text { militares sostenidas } \\
\text { y concertadas" }\end{array}$ & No lo establece & No lo establece \\
\hline $\begin{array}{l}\text { Prolongación del } \\
\text { conflicto }\end{array}$ & No lo establece & No lo establece & $\begin{array}{c}\text { El conflicto } \\
\text { armado debe ser } \\
\text { prolongado }\end{array}$ & No lo establece \\
\hline Ratione Loci & $\begin{array}{c}\text { El conflicto debe } \\
\text { desarrollarse en el } \\
\text { territorio de un } \\
\text { Estado Parte }\end{array}$ & $\begin{array}{c}\text { El conflicto debe } \\
\text { desarrollarse en el } \\
\text { territorio de un } \\
\text { Estado Parte }\end{array}$ & $\begin{array}{c}\text { El conflicto debe } \\
\text { desarrollarse en el } \\
\text { territorio de un } \\
\text { Estado Parte }\end{array}$ & $\begin{array}{c}\text { El conflicto debe } \\
\text { desarrollarse en el } \\
\text { territorio de un } \\
\text { Estado Parte }\end{array}$ \\
\hline
\end{tabular}

Fuente: elaboración propia, basada en Ferro y Vité. ${ }^{31}$

${ }^{31}$ Ferro, art. cit., Vité, art. cit. 
Como se puede apreciar, se contemplan los cuatro instrumentos previamente señalados y los requisitos se agrupan en siete categorías: la naturaleza de los actores involucrados; el nivel de intensidad del conflicto; el nivel de organización de los grupos insurgentes; el control territorial; la existencia de operaciones militares; la duración del conflicto y el elemento de ratione loci, que se refiere al ámbito de aplicabilidad del tratado en cuestión.

Tipificación Jurídica: ¿EXiste o nO un CANI en México?

A continuación, analizamos cada uno de estos criterios para determinar en qué medida se cumplen en el caso de México . Además de revisar los elementos solicitados expresamente en los instrumentos jurídicos, se atenderán también los comentarios autorizados del Comité Internacional de la Cruz Roja (CICR) sobre su interpretación. Esta organización internacional desempeña el cometido de "guardián" del DIH y, entre otras, tiene la labor de reflexionar sobre la aplicación, interpretación y evolución del derecho internacional humanitario, a fin de buscar respuestas adecuadas a los problemas que se plantean y de propiciar el desarrollo de ese derecho.

\section{I) Actores involucrados}

El artículo $3^{\circ}$, el Estatuto de Roma y el caso Tadic reconocen conflictos en los cuales no necesariamente interviene el ejército de un Estado. El Protocolo Adicional II, por su parte, sí establece la necesidad de que participen las fuerzas armadas. En México hay luchas entre grupos del crimen organizado, pero también entre ellos y el Estado. Por lo tanto, el caso mexicano cumple con el elemento requerido por las cuatro definiciones. 


\section{II) Intensidad del conflicto y III) Organización de los grupos armados}

De acuerdo con el CICR, en la práctica jurídica se alcanza la condición de conflicto cuando la situación puede definirse como de "violencia armada prolongada" ${ }^{32}$ Esta condición debe evaluarse conforme a dos criterios fundamentales: la intensidad de la violencia y la organización de las partes.

a) Intensidad de la violencia

Según los criterios del CICR, para determinar la intensidad se debe considerar la índole colectiva de los combates o el hecho de que el Estado esté obligado a recurrir a sus fuerzas armadas para atender la situación; la duración de los enfrentamientos armados y su frecuencia, las armas utilizadas, el desplazamiento de población, el control territorial de grupos armados y la cantidad de víctimas. ${ }^{33}$

Argumentando una falta de capacidad en las fuerzas policiales, el ejército ha sido -y continúa siendo- el principal actor en combatir el crimen organizado. En México, una estrategia militarizada, centralizada y enfocada en la oferta, fue la constante en las administraciones de Felipe Calderón (2006-2012) y Enrique Peña Nieto (2012-2018). ${ }^{34}$ En 2010 se estimaba que había al menos 45000 soldados mexicanos cumpliendo labores de policía, mientras que todos los miembros de la Policía Federal Preventiva alcanzaban apenas una proporción similar de 35000 elementos. ${ }^{35}$ El gobierno del expresidente Peña Nieto, a pesar de haber criticado en campaña la militarización iniciada por Felipe Calderón, incre-

32 CICR, art. cit., 2011.

33 Vité, art. cit.

34 A. Piaggio y P. Vidwans, The cost and consequences of the war on drugs, Nueva York, Human Rights Foundation, 2019.

${ }^{35}$ A. Alvarado y J. Zaverucha, "La actuación de las fuerzas armadas en la seguridad pública en México y Brasil: una visión comparada”, en Arturo Alvarado y Mónica Serrano (eds.), Seguridad nacional y seguridad interior, México, El Colegio de México, 2010, pp. 228-264. 
mentó el número de tropas militares en $50 \%$ en comparación con la administración previa. ${ }^{36}$

El actual gobierno de Andrés Manuel López Obrador (2018-2024) ha argumentado la necesidad de replantear la estrategia de seguridad e implementar acciones que privilegien la seguridad ciudadana, enfatizando el combate a la desigualdad, la corrupción y la impunidad, y destinar esfuerzos que favorezcan el fortalecimiento de vínculos sociales que permitan la reconciliación. ${ }^{37}$ Sin embargo, para el combate al crimen, ha creado la figura de la Guardia Nacional, que busca reclutar cerca de 150000 ciudadanos $^{38}$ y que, para muchos, es el ejército bajo un uniforme distinto, representando una continuación de la estrategia militarizada. ${ }^{39}$

Además de la participación del Ejército, cabe destacar que de acuerdo con investigaciones del Centro de Investigación y Docencia Económica (CIDE), en México han aumentado no sólo los enfrentamientos, sino los índices de letalidad, ${ }^{40}$ superando incluso aquellos registrados en guerras tradicionales. La guerra de Vietnam tuvo una relación de cuatro muertos por cada herido; el conflicto entre Israel y Líbano tuvo un índice de 4.5 y la guerra del Golfo uno de tres. ${ }^{41}$ Por su parte, en el periodo 2007-2014, la Policía Federal mexicana tuvo un saldo de 4.8 civiles muertos por cada civil herido, mientras

${ }^{36}$ J. D. Rosen y R. Zepeda, "Una década de narcoviolencia en México: 2006-2016” (pp. 55-65), en R. Benítez Manaut y S. Aguayo Quezada (eds.), Atlas de la seguridad y la defensa de México 2016, México, Senado de la República, Instituto Belisario Domínguez, Colectivo de Análisis de la Seguridad con Democracia, Casede, 2017.

37 México, Presidencia de la República, Plan Nacional de Desarrollo 2019-2024, México, abril de 2019, 64 pp.

38 A. Hope, "La Guardia Nacional: todos la quieren”, El Universal, 15 de mayo de 2019, https:/ / www.eluniversal.com.mx/columna/alejandrohope/nacion/la-guardia-nacional-todos-la-quieren

39 Piaggio y Vidwans, op. cit., p. 30.

${ }^{40} \mathrm{El}$ índice de letalidad es el número de civiles muertos por cada civil herido en enfrentamientos.

41 Catalina Pérez Correa, Silva Forné y R. Gutiérrez Rivas, "Índice de letalidad. Menos enfrentamientos, más opacidad”, Nexos, 1 de julio de 2015. 
que el del Ejército llegó a 7.9. De acuerdo con este texto, ${ }^{42}$ la información oficial no permite calcular el índice de letalidad de la Marina, ya que en la columna correspondiente a "civiles heridos" señaló "sin datos" en $85 \%$ de los enfrentamientos reportados. Con la información de prensa se calcula que fue de 25 en 2010; 14.7 en 2011; 36 en 2012; 16.5 en 2103 y 74 en $2014 .^{43}$

Sobre la duración del conflicto, es razonable suponer que más de 14 años de enfrentamientos acreditan la condición de un conflicto prolongado, a diferencia de lo que serían disturbios esporádicos.

En cuanto a las armas, en México se observa el uso cotidiano de las R-15 y AK-47, ametralladoras calibre $7.62 \mathrm{~mm}$, explosivos C-4, cohetes antitanques M72 y AT-4, lanzacohetes RPG-7, lanzagranadas MGL calibre $37 \mathrm{~mm}$., granadas de 37 y $40 \mathrm{~mm}$., fusiles Barret calibre .50 y fusiles Galil, lanzacohetes y armas con capacidad para disparar municiones calibre $5.7 \times 28$, idóneas para penetrar distintos tipos de blindajes. También se ha detectado el uso de minas antipersonales. Todas ellas forman parte de las armas más utilizadas en conflictos armados y algunas están prohibidas por tratados internacionales, como es el caso de las minas antipersonales. ${ }^{44}$ Según datos oficiales, entre 2006 y 2012 fueron decomisados 81 lanzacohetes de tipo RPG a organizaciones delictivas. ${ }^{45}$

Por otra parte, y de acuerdo con figuras del Banco Mundial sobre desplazamiento interno de población, en 2017 México registraba 345000 ciudadanos desplazados debido al conflicto y la violencia, pero otras organizaciones argumentan que el número real podría incluso rebasar los 1.5 millones. ${ }^{46}$

${ }^{42}$ Loc. cit.

${ }^{43}$ Crawford, 2013, en Pérez, Loc. cit.

${ }^{44}$ N. Sandoval Ballesteros, "México en guerra", Proceso, 2 de febrero de 2012.

${ }^{45} \mathrm{~J}$. Paullier, “¿De dónde salen las armas pesadas del narco en México?”, BBC, 6 de mayo de 2015.

${ }^{46}$ Piaggio y Vidwans, op. cit., p. 35. 
Sobre el control territorial, en 2010 el secretario de Gobernación, Francisco Blake Mora, afirmó que el número de municipios dominados por el narcotráfico en México era superior a 400 ayuntamientos. ${ }^{47}$ Por su parte, investigadores de la Universidad Nacional Autónoma de México (UNAM) destacaron que las estimaciones estaban muy por debajo de la realidad: Jiménez Ornelas, ${ }^{48}$ coordinador de la Unidad de Análisis sobre Violencia Social de esa institución académica, afirmó que ese número podría ser superior a $900 .{ }^{49}$ Para valorar cabalmente esta cifra hay que tomar en cuenta que en México existen actualmente 2446 municipios y que de 2004 a 2012 el porcentaje de municipios capturados por la delincuencia no dejó de aumentar; ${ }^{50}$ se estima que la expansión territorial local pasó de $34 \%$ de municipios controlados en 2001, a 71.5\% en 2012.51

En 2015, la oficina de la Drug Enforcement Administration (DEA) dio a conocer el mapa que muestra las zonas de presencia dominante de los cárteles en México. Este mapa ha sido actualizado y difundido por quienes investigan el fenómeno (véase mapa 1).

Como se puede apreciar, los cárteles cuentan con presencia y control territorial en prácticamente todo el territorio mexicano.

Respecto a las víctimas, de 2007 a 2018 se atribuyen 227428 homicidios al conflicto relacionado con el narcotráfico, ${ }^{52}$ cifra que asciende a 262007 cuando se añaden los de 2019.53

${ }^{47}$ F. Martínez, "Al gobierno le ha faltado organización en la lucha anticrimen, reconoce Blake", La Jornada, 27 de octubre de 2010, https:/ / www.jornada.com.mx/2010/10/27/politica/003n1pol

${ }^{48}$ René Alejandro Jiménez Ornelas, citado en A. Becerril, V. Ballinas, C. Gómez y J. A. Román, "Más de 400, los municipios bajo control del narco: legisladores y académicos", La Jornada, 28 de octubre de 2010.

${ }^{49}$ Loc. cit.

${ }^{50}$ Cruz Santiago, op. cit.

${ }^{51}$ C. Rodríguez, Contacto en Italia: el pacto entre los Zetas y la Ndrangueta, México, Debate, 2009. J. Fernández, Las FARC en México: de la política al narcotráfico, México, Editorial Nuevo Siglo/Aguilar, 2008.

${ }^{52}$ Piaggio y Vidwans, op. cit.

${ }^{53}$ P. Sánchez Olmos, "2019, el año más sangriento de la historia reciente de México", El Mundo, 24 de diciembre de 2019, https://www.elmundo.es/internacional/2019/12/24/5e00fa36fdddffff808b4604.html 
Por su parte, el gobierno reconoce actualmente 61000 personas desaparecidas en el país, cuyos casos ocurrieron en su gran mayoría después de $2006 .{ }^{54}$ En el reporte de 2020 sobre el índice de paz en México, la tasa de homicidios ascendía a 28.1 por cada 100000 habitantes, ubicándose en su nivel más alto desde 1990, año en que empezó a tenerse registros oficiales. ${ }^{55}$ Estas cifras son aún más graves en un país donde la cifra negra es elevada: el 93.2\% de los delitos en México en 2019 no se incluyeron en las estadísticas oficiales porque no se denunciaron ante las autoridades o porque no se abrió una investigación. ${ }^{56}$

En este sentido, el conflicto mexicano sin duda constituye un escenario de violencia generalizada, hecho reconocido por organismos internacionales como Amnistía Internacional y la Organización de Naciones Unidas (ONU)..$^{57}$

En síntesis, considerando la cada vez mayor presencia del Ejército en las calles, el índice de letalidad de las fuerzas armadas y de la policía, las armas utilizadas, el desplazamiento de la población, el control territorial de los cárteles y el número de víctimas y desaparecidos, es posible afirmar que en México se cumple sobradamente el criterio de intensidad. Cabe señalar que, si bien todos éstos son indicadores de evaluación, no son condiciones que deban existir simultáneamente para cumplir con la tipificación, ${ }^{58}$ aunque en el caso de México así sucede.

${ }^{54}$ M. Wattenbarger, "La búsqueda de respuestas en México", Nacla, 13 de abril de 2020, https://nacla.org/news/2020/04/17/5a-brigada-nacio nal-mexico

55 Institute for Economics and Peace, Índice de paz México 2020, Sídney, 2020, indicedepazmexico.org

${ }^{56}$ Loc. cit.

${ }^{57}$ Amnistía Internacional, Informe Anual 2016/2017. Desigualdad e impunidad principales obstáculos para los derechos humanos, México, 2017 y G. Sotomayor, "Preocupa a onu 'violencia generalizada' en México", Panorama. Red Internacional de Derechos Humanos, Ginebra, 5 de mayo de 2015.

58 Vité, art. cit. 
MAPA 1

Zonas de presencia dominante de los cárteles en México

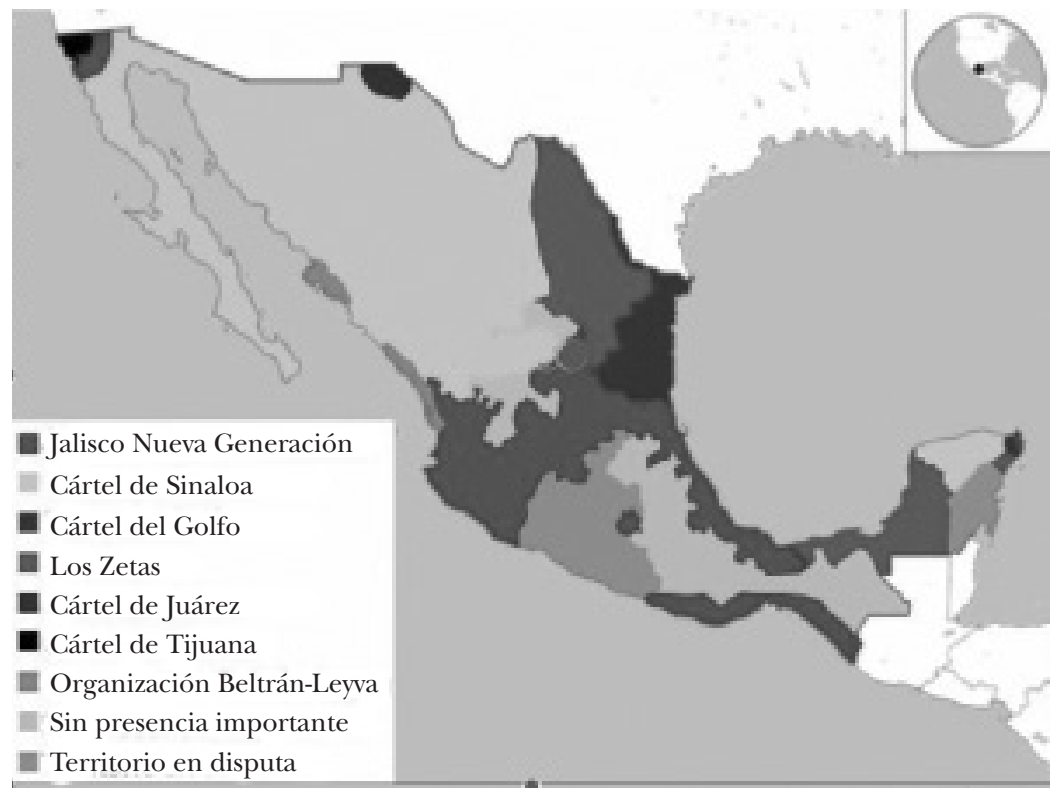

Fuente: A. Nájar, "Los mapas que muestran los radicales cambios de influencia territorial de los cárteles del narcotráfico en México”, BBC Mundo, 11 de julio de 2017.

A continuación analizaremos el cumplimiento del criterio de organización, para determinar si las organizaciones criminales mexicanas cumplen también con éste.

b) Organización de los grupos armados De acuerdo con el CICR:

La cuestión es saber si la violencia a que da lugar el crimen organizado y la forma en que se responde a él se pueden considerar un conflicto armado según el DiH y, en especial, si los grupos armados implicados en el crimen organizado pueden ser partes en un conflicto armado. La respuesta dependerá de los dos criterios principales utilizados para determinar la exis- 
tencia de un CANI: el nivel de organización de las fuerzas implicadas y la intensidad de la violencia. [...] En muchos contextos se cumple el primer criterio. Los grupos criminales cuentan, a menudo, con una estructura de mando, un centro de operaciones, la capacidad de procurarse armas y de planificar operaciones, etcétera. ${ }^{59}$

Sobre el nivel organizativo, ${ }^{60}$ que es el que se discute en este punto, cabe retomar a Villaverde y Blanco, ${ }^{61}$ quienes señalan que los cárteles mexicanos cuentan con mecanismos de seguridad e inteligencia; cobran impuestos y derecho de piso,

${ }^{59}$ CICR, 2011, p. 13.

${ }^{60}$ En realidad, el nivel organizativo del Estado mexicano ha llegado a ser más cuestionado que el de los cárteles. Diversos autores señalan que el fortalecimiento de los grupos criminales es consecuencia de la pobre organización y coordinación de las instituciones mexicanas para combatirlos (J. C. Montero, "La estrategia contra el crimen organizado en México: análisis del diseño de la política pública", Perfiles Latinoamericanos 20, núm. 39, 2012; V. Ríos, "How Government Structure Encourages Criminal Violence: The Causes of Mexico's Drug War", Disertación para obtener el grado de Doctor of Philosophy, Cambridge, Harvard University, 2012); de la narcorrupción, es decir del desarrollo de redes de colusión y cooperación entre oficiales, policías y militares del Estado y grupos criminales (J. Chabat, "Seguridad nacional y narcotráfico: Vínculos reales e imaginarios". Política y gobierno, vol. 1, núm. 1, (1994), pp. 97-123. Jorge Chabat, "Narcotráfico y estado: El discreto encanto de la corrupción", Letras Libres, 20 de septiembre de 2005; C. Flores, El Estado en crisis: crimen organizado y política. Desafíos para la consolidación democrática, México, Centro de Investigaciones y Estudios Superiores de Antropología Social, 2009; C. Flores, "La lógica del botín: de la cooptación del Estado y el Estado fallido", en Arenas, 13, 30 (2012), pp. 11-44; Montero, art. cit.), y de las pobres condiciones económicas del mercado de trabajo en México, que inducen a los jóvenes desempleados a unirse a los grupos criminales como medio de subsistencia (V. Ríos, "To Be or Not To Be a Drug Trafficker: Modeling Criminal Occupational Choices", Documento de trabajo presentado en la Conferencia Anual del Midwest Political Science Association, 2010.

${ }^{61}$ J. C. Villaverde y J. M. Blanco, "El crimen organizado y la estabilidad estatal en México", I Congreso Internacional de Estudios Militares, Granada, 2014. 
controlan el suministro de bienes estratégicos como los energéticos; venden sus productos; difunden su cultura, su religión; silencian medios de comunicación; utilizan el poder político, policial e incluso judicial y, finalmente, ejercen liderazgo en territorios donde el Estado, ya sea por incapacidad o por corrupción, no alcanza a gobernar.

Hasta aquí se cumplen los estándares de organización del artículo $3^{\circ}$ Común, el Estatuto de Roma y el caso Tadic. Por su parte, el PA II establece criterios aún más estrictos, al requerir la capacidad de dirigir operaciones militares. A este respecto, el CICR añade como elementos a considerar la existencia de un organigrama que refleje una estructura de mando, la autoridad para lanzar operaciones que involucren a distintas unidades, la capacidad de reclutar y entrenar combatientes, y la existencia de reglas internas. ${ }^{62}$

$\mathrm{Al}$ respecto, Hurtado y García sostienen que:

Las organizaciones de narcotraficantes generalmente cuentan con una estructura de dirección y mando bien definidos, operan por medio de células y rangos de autoridad, cuentan con grupos de sicarios y cuerpos de seguridad propios, establecen controles territoriales, tienen sistemas de comunicación y armamento moderno, vehículos, casas de seguridad y una gran capacidad financiera. [...] Su capacidad operativa y económica les ha permitido desarrollar técnicas cada vez más sofisticadas para rebasar las capacidades de los controles fronterizos y de seguridad de los Estados. ${ }^{63}$

De acuerdo con la DEA, ${ }^{64}$ los cárteles mexicanos suponen la mayor amenaza criminal relacionada con las drogas para EEUU, ya que ningún otro grupo está posicionado actual-

${ }^{62}$ Loc. cit.

${ }^{63}$ O. Hurtado y R. García, "El narcotráfico en México como problema transnacional", Revista mexicana de política exterior, 97, 2013, p. 39.

${ }^{64}$ Drug Enforcement Administration, DEA, 2015 National Drug Threat Assessment Summary, U.S. Department of Justice; Drug Enforcement Administration, 2015. 
mente para desplazarlos. En ese mismo informe señalan que las operaciones de los cárteles mexicanos en EEuU tienden a tomar la forma de una cadena de suministro que funciona según la demanda: el sistema emplea operadores independientes que sólo están enterados de su propia y muy específica función, y desconocen los demás aspectos de la operación. Si uno de ellos es arrestado, además de reemplazarlo con facilidad, será incapaz de revelar información sobre el resto del operativo o de la organización misma. En la página oficial de la Office of Foreign Assets Control del U.S. Department of the Treasury pueden encontrarse varios organigramas de cárteles mexicanos y colombianos que ilustran algunos aspectos de su organización interna. ${ }^{65}$

Respecto al reclutamiento, pueden señalarse los hallazgos de campos de entrenamiento, ${ }^{66}$ indicios de la participación de soldados estadunidenses ${ }^{67}$ y de mexicanos que estuvieron presos en Estados Unidos y fueron deportados; ${ }^{68}$ de migrantes centroamericanos que han sido secuestrados y obligados a trabajar para el crimen, ${ }^{69}$ así como de miles de jóvenes mexicanos que deciden involucrarse en actividades de narcotráfico, frecuentemente debido a la ausencia de mecanismos de movilidad social. ${ }^{70}$

Y finalmente, respecto a la existencia de reglas internas -sin las cuales es evidente que los cárteles no tendrían el poder y nivel de organización que efectivamente tienen- Andrade señalaba ya en 1999 que "la ley ahí es otra cosa, sujeta a reglas armadas durante décadas, que tienen muy poco que

65 J. J. Esquivel, "Cárteles mexicanos, amos del mercado estadounidense de heroína y anfetaminas", Proceso.

66 "Aseguran tres campos de entrenamiento del narco en Tamaulipas”, Proceso, 29 de julio de 2015.

67 "Cárteles mexicanos contratan soldados de eu como sicarios y capacitadores", La Jornada, 2 de agosto de 2013.

68 G. Castillo García, "ssp: los cárteles La Línea y La Familia reclutan a mexicanos en penales de EU", La Jornada, 18 de agosto de 2010.

69 J. Gil Olmos, "Los nuevos 'esclavos' de los cárteles”, Proceso, 2012.

${ }^{70}$ Cruz Santiago, op. cit. 
ver con nuestro marco legal, pero que al mismo tiempo hacen funcionar una maquinaria impresionante de hacer dinero". ${ }^{71}$

Retomando lo anterior, se puede afirmar que en el caso mexicano se cumplen cabalmente tanto los elementos de intensidad del conflicto como los de organización de los grupos armados.

\section{Control territorial}

Únicamente el PA II contiene una exigencia territorial específica, al establecer que los conflictos armados serán aquellos en que los grupos beligerantes "bajo la dirección de un mando responsable, ejerzan sobre una parte de dicho territorio un control tal que les permita realizar operaciones militares sostenidas y concertadas y aplicar el presente Protocolo”.

De acuerdo con Vité ${ }^{2}$ el nivel de control territorial suele evaluarse de distintas maneras: si se adopta una interpretación amplia, incluso el control temporal de zonas reducidas sería suficiente para justificar la aplicación del Protocolo Adicional II; por el contrario, una interpretación estricta del artículo obliga a limitar las situaciones comprendidas en éste a aquellas en las cuales la parte no gubernamental ejerce un control similar al de un Estado. El CICR formula su interpretación desde una postura intermedia: acepta que el control territorial tenga un carácter relativo, por ejemplo, cuando los centros urbanos permanecen en poder gubernamental, mientras que las zonas rurales escapan a su autoridad, pero requiere "cierta estabilidad en el control de una porción del territorio, aunque sea modesta”. ${ }^{73}$

${ }^{71}$ Entre las leyes más básicas están las relacionadas con el dinero que se debe entregar a las viudas del narco. Para quien viole los acuerdos están Los Cobradores, quienes se encargan de mantener el orden y respeto a las tradiciones. J. Andrade Jardí, "Las leyes del narco. La plata, el plomo y San Judas Tadeo", Nexos, 1 de octubre de 1999.

72 Vité, art. cit.

${ }^{73}$ Loc. cit. 
En la interpretación amplia o en la del CICR, tanto el índice de cooptación de municipios como el mapa de la DEA y la BBC parecen más que suficientes para acreditar el elemento territorial. Pero inclusive en una interpretación estricta, el caso mexicano cumple los criterios: regiones rurales de Michoacán, Sinaloa, Durango, Chihuahua, Tamaulipas y Guerrero, por mencionar algunas, son casos paradigmáticos de control territorial prolongado por el narcotráfico.

Los cárteles han llegado a ocupar roles similares a los del Estado, estableciendo soberanías paralelas y consolidando enclaves criminales en grandes áreas en México. En esas regiones conocidas como "zonas sin ley", "espacios sin gobierno" o "zonas de impunidad", las bandas criminales han impuesto arreglos políticos de tipo neofeudal, como el cobro de impuestos o derecho de piso y el aprovisionamiento de bienes sociales.

A partir de la evidencia anteriormente expuesta, es posible sostener que los cárteles cuentan con la característica de control territorial enunciada por el PA II.

\section{OPERACIONES MILITARES SOSTENIDAS Y CONCERTADAS}

De acuerdo con el CICR:

El control sobre una parte del territorio del Estado que permita realizar operaciones militares continuadas y hacer aplicar, de manera responsable, las disposiciones del derecho humanitario, confirma que se trata, en realidad, de un conflicto, y no de un enfrentamiento pasajero o de enfrentamientos esporádicos, entre el Estado y quienes al Estado se oponen. ${ }^{74}$

No es suficientemente claro si el desarrollo de dichas operaciones constituye un elemento independiente o si hace referencia a un factor para evaluar el control territorial, la

${ }^{74}$ Swinarski, art. cit. 
intensidad del conflicto o su prolongación. Si constituye simplemente un indicador, éste sería sólo un factor -entre otros- a considerar y, por lo tanto, su ausencia no sería motivo suficiente para rechazar la clasificación de conflicto armado. ${ }^{75} \mathrm{Si}$, en cambio, se tratara de un nuevo requisito, sería más difícil discernir su cumplimiento.

Como afirma el IIss, en México ocurren regularmente enfrentamientos entre grupos criminales y fuerzas de seguridad. Ciertos cárteles, como los Zetas y más recientemente el Cártel de Jalisco Nueva Generación (CJNG), han adoptado estrategias de "criminalidad militarizada"76 para controlar los territorios. El número de asesinatos se disparó en un $22.8 \%$ entre 2015 y 2016.77

De acuerdo con datos obtenidos de la Estadística del personal militar y civiles agresores fallecidos y heridos con motivo de las agresiones a personal militar, elaborado por la Secretaría de la Defensa Nacional (Sedena), y el oficio 946/17 de la Unidad de Transparencia de la Secretaría de Marina (Semar), las fuerzas armadas mexicanas han registrado 4276 enfrentamientos armados en 10 años y medio de lucha contra el narcotráfico. ${ }^{78}$

Garduño Valero, ${ }^{79}$ especialista en fuerzas armadas y seguridad nacional, afirma que estas cifras evidencian que México

${ }^{75}$ Los indicadores de intensidad, dice el CICR, constituyen factores de evaluación que permiten establecer si se ha alcanzado el nivel mínimo de intensidad en cada caso, pero no son condiciones que deban existir simultáneamente. Véase Vité, art. cit.

76 "El IIss observó que los Zetas -en su tiempo-y, más recientemente, el Cártel Jalisco Nueva Generación (CJNG), adoptaron estrategias de 'criminalidad militarizada', que consistieron en ataques frontales contra la policía y las fuerzas armadas, así como el uso de métodos de 'criminalidad híper violenta', como la decapitación, el 'cobro de piso', o las extorsiones, para sentar sus dominios sobre los territorios y sus habitantes", "Reporte del IIss sobre la violencia en México 'carece de rigor técnico': Segob y SRE", Proceso, 10 de mayo de 2017.

77 Loc. cit.

78 Z. Camacho, "Fuerzas Armadas: más de 4 mil enfrentamientos con el narco”, Contralinea, 2017.

${ }^{79}$ Citado en Loc. cit. 
está en guerra. Lo anterior, aunado al número de víctimas mortales, "nos habla incluso de una guerra encarnizada; pero es una guerra no convencional, contra actores no estatales".

Sin embargo, precisamente porque los actos de violencia tienden a estar dirigidos contra la población civil, y a que el CICR no propone parámetros para determinar lo que constituyen "operaciones militares sostenidas", dependerá de la interpretación que se dé a dicha exigencia el considerar o no su cumplimiento en el caso de México.

Si el PA II efectivamente exige como un elemento independiente el que las organizaciones criminales lleven a cabo operaciones militares sostenidas, es posible que este criterio no se cumpla. Sin embargo, esto se debería a la naturaleza misma de los cárteles y su forma de operar. No les falta control territorial, capacidad militar o de organización para realizar tales operaciones; el que no utilicen el control territorial para este propósito responde más a una decisión pragmática que a incapacidad.

De acuerdo con Chabat, ${ }^{80}$ la relación entre el narcotráfico y el Estado tiene tres modalidades: confrontación, corrupción y coexistencia pacífica. La confrontación ocurre cuando el narcotráfico comienza a crecer y a desafiar al Estado. Esta modalidad no es funcional para el negocio, es más bien un síntoma de reacomodo entre ambos actores. La segunda forma es la corrupción, que va más allá de limitarse a "no ver": "Se paga para no ser detenido; para en caso de serlo, no ser condenado y, en caso de serlo, poder escapar de la prisión; se paga por información sobre operativos policiacos, por información sobre las bandas competidoras e incluso se paga por usar al Estado en contra de los enemigos". La tercera modalidad es la de la coexistencia pacífica. Normalmente se piensa que la razón por la cual un Estado no combate al narcotráfico de manera suficiente es la corrupción. Sin embargo, hay otras dos posibles razones: porque no puede o porque no le conviene. El narcotráfico tiene un impacto significativo

${ }^{80}$ Chabat, art. cit. 
en las economías en que opera: genera empleos, alivia la demanda de servicios básicos, invierte en negocios lícitos y contribuye a resolver desequilibrios de la balanza de pagos. Adicionalmente, los lazos se estrechan cuando el crimen organizado financia las campañas electorales de algunos actores políticos. ${ }^{81}$

De acuerdo con este autor, el narcotráfico no busca la desaparición del Estado ni tampoco una vinculación ostensible. Un gobierno abiertamente coludido les resultaría disfuncional, debido a que intensificaría la crítica de la opinión pública, así como la presión internacional, mientras que al crimen le conviene más la discreción y el anonimato. Buscan solamente un Estado que los deje operar, que los proteja, que trabaje para ellos o con ellos. ${ }^{82}$

Será imperativo recordar la relación especial entre el crimen y las autoridades en el contexto de la guerra contra el narcotráfico. Esta relación difiere de aquella que se da entre contendientes bélicos convencionales, donde se busca derrocar al contrincante, y no únicamente debilitarlo o cooptarlo.

En México, los grupos criminales establecen su base operativa en los municipios donde pueden controlar y dominar con mayor facilidad el territorio, y luchan entre ellos para capturar a políticos, policías y fiscales. Esto ocurre a través de extorsiones o amenazas, mediante el financiamiento de campañas políticas, sobornos a bajo nivel o al colocar a un miembro o aliado del grupo criminal en un cargo público. ${ }^{83}$

En el caso mexicano, sus capacidades financieras y operativas les han permitido penetrar en la esfera política y económica del país, ${ }^{84}$ erosionar instituciones gubernamentales,

${ }^{81}$ Loc. cit.

${ }^{82}$ Loc. cit.

83 Cruz Santiago, op. cit.

84 De acuerdo con Garzón, el crimen organizado ha demostrado ser un sistema de relaciones políticas, sociales y económicas. La facción criminal -cártel, banda, comando o mara- es la parte más visible del sistema, pero en modo alguno constituye su totalidad. En la base se encuentran un conjunto de relaciones complejas, que establecen conexiones entre 
incidir en las estructuras sociales y disputar el control del Estado en varias regiones. Su enorme poder de corrupción ha alcanzado sectores vitales para la sociedad mexicana, como son los de seguridad y de procuración e impartición de justicia. ${ }^{85}$

Cada uno de los principales cárteles mexicanos invierte, en promedio, 40 millones de dólares americanos anuales para sobornos a jueces. ${ }^{86} \mathrm{El}$ financiamiento de precampañas políticas es otro medio utilizado, en tanto que facilita el lavado de dinero y la compra de políticas públicas. ${ }^{87}$

Como evidencia del vínculo entre grupos de delincuencia organizada e instituciones municipales, estatales y federales, están las numerosas denuncias de periodistas y defensores de derechos humanos, ${ }^{88}$ así como el hecho de que en di-

los mundos legal e ilegal y se asientan en las deficiencias de los Estados, emergiendo como poderes autónomos basados en la criminalidad. J. Garzón, "El futuro del narcotráfico y los traficantes en América Latina", en Atlas de la Seguridad y la Defensa de México 2012, México, Colectivo de Análisis de la Seguridad con Democracia A.C. (Casede).

${ }^{85}$ Hurtado y García, art. cit.

${ }^{86}$ E. Buscaglia, S. González-Ruiz y C. Prieto Palma, "Causas y consecuencias del vínculo entre la delincuencia organizada y la corrupción a altos niveles del Estado: mejores prácticas para su combate", Terrorismo y delincuencia organizada. Un enfoque de derecho y economía, Mexico, IIJ/UnAM, 2006, pp. 87-102.

${ }^{87}$ Loc. cit.

${ }^{88}$ Cruz Santiago, op. cit; En un reciente estudio coordinado por investigadores de El Colegio de México sobre las matanzas de San Fernando, Tamaulipas y Allende, Coahuila, se reporta que en ambos casos los Zetas contaron con la cooperación de la policía local, no porque ésta participara de manera directa, sino más bien porque sus miembros "miraron para otro lado" y denegaron el auxilio a las familias que denunciaban los hechos (L. de la Calle, "La ¿interminable? guerra contra el narco en México", CTXT (88), 2016.) También se puede referir a la detención del Fiscal General de Nayarit, Édgar Veytia, acusado de conspirar para manufacturar, importar y distribuir drogas en México y eeuu (P. Dávila, "Cae en San Diego, California, fiscal de Nayarit, Édgar Veytia, vinculado al narco", Proceso, 29 de marzo de 2017). El Informe "Control Sobre Todo el Estado de Coahuila", realizado por la Clínica de Derechos Humanos de la Facultad de Derecho de la Universidad de Texas, analiza los juicios contra exinte- 
versas regiones del país, ante la falta de control territorial y protección estatal, la ciudadanía haya optado por ejercer la justicia por propia mano. ${ }^{89}$

Por lo tanto, el desarrollo de operaciones militares sostenidas, presente únicamente en el PA II, pudiera no cumplirse cabalmente en el caso de México. Esto ocurriría si es analizado como un elemento independiente y no como mero indicador. Sin embargo, sería cuestionable su exigencia al considerar la naturaleza y forma de operar del crimen organizado, cuyos propósitos son económicos y no políticos, y cuya violencia se dirige con más frecuencia contra la población civil que contra las autoridades.

Adicionalmente, tanto los criterios de organización de las partes combatientes, así como el de operaciones militares sostenidas, son cuestionables de cara a los conflictos bélicos contemporáneos, cuya naturaleza, métodos e instrumentos pueden ser distintos a los de guerras convencionales, pero no por ello menos violentos y a los que es urgente regular.

Un caso particular que ilustra lo estricto del Protocolo Adicional II es el de Ruanda donde, siguiendo a Ferro, ${ }^{90}$ este tratado sería inaplicable:

En este caso, como en tantos otros, las fuerzas armadas locales se encontraban completamente desintegradas como resultado

grantes de Los Zetas en los que refieren al apoyo que obtuvieron de policías municipales, de los gobiernos estatal (los exgobernadores Humberto y Rubén Moreira) y federal en sus actividades delictivas (J. A. Cedillo, "Informe revela control de Los Zetas en Coahuila durante los gobiernos de los hermanos Moreira”, Proceso, 6 de noviembre de 2017). Otro caso de colusión involucra al exgobernador de Tamaulipas, Tomás Yarrington, quien facilitó y participó en las actividades de los cárteles del Golfo, de Los Zetas y de los hermanos Beltrán Leyva de 1999 a 2009 a cambio de millones de dólares (I. Savio, "Al servicio del narco: pruebas documentales y testimonios hunden a Yarrington”, Proceso, 11 de noviembre de 2017).

89 O. D. Rodríguez Fuentes, "El limbo democrático: Estado de derecho, crimen organizado y paramilitarismo en México", Politai: Revista de Ciencia Política, núm. 11, 2015, pp. 15-32.

${ }^{90}$ Ferro, art. cit. 
de la fragilidad del Estado, y la violencia inicial no era producida por grupos armados organizados bajo un mando responsable sino creados de forma caótica, casi espontánea. Así podría pensarse que la mayoría, sino todos, los conflictos que se desarrollan en un Estado Fallido quedarían por fuera del campo de aplicación del Protocolo Adicional II. ${ }^{91}$

Considerando lo anterior, se puede plantear que el criterio de operaciones militares se cumple parcialmente en el caso de México. Sin embargo, esto sugiere la necesidad de revisar, examinar y repensar la aplicabilidad del marco jurídico actual del DiH para conflictos contemporáneos.

\section{Prolongación DEL CONFLicto}

La referencia explícita a la existencia de un enfrentamiento prolongado se encuentra en el Estatuto de Roma. Con ella se busca distinguir entre conflictos armados y disturbios interiores o tensiones internas, conceptos que designan tipos de inestabilidad social que no pertenecen al ámbito de los conflictos armados y que nunca han sido definidos en el derecho. "Los conflictos armados no internacionales han de distinguirse de las formas de violencia colectiva de menor nivel, como los disturbios civiles, los motines, los actos de terrorismo aislados u otros actos de violencia esporádicos". 92

El conflicto en México, que ha durado más de 14 años, en modo alguno puede ser reducido a una violencia colectiva de menor nivel. Por consiguiente, se puede afirmar que sin duda cumple con el elemento señalado en el Estatuto de Roma.

${ }^{91}$ Ibid., p. 8

${ }^{92}$ Lawand, art. cit. 


\section{RATIONE LOCI}

Este último elemento, común a las cuatro definiciones, establece que la situación de conflicto armado debe tener lugar en el territorio de un Estado parte contratante. México es parte de los cuatro Convenios de Ginebra de 1949 desde el 29 de octubre de 1952 y, desde el 10 de marzo de 1983, lo es también del Protocolo Adicional I de 1977. Sin embargo, México es el único Estado del continente americano que todavía no ha ratificado el Protocolo Adicional II. ${ }^{93}$ A su vez, el Estatuto de Roma fue firmado en 2000 y ratificado en 2005. Por su parte, la sentencia del caso Tadic supone una base jurídica -jurisprudencia- para que en casos similares se utilice la misma definición de conflicto armado interno.

Retomando todos los criterios analizados, el escenario mexicano cumple con los requerimientos del artículo 3, el Estatuto de Roma y de la jurisprudencia del caso Tadic v. Prosecutor. Únicamente en el Protocolo Adicional II, instrumento no vigente en México, hay un cumplimiento parcial en el caso de las operaciones militares sostenidas.

\section{Dos objeciones en contra de la tipificación como CANI}

Hasta este momento se ha mostrado que la guerra contra el narcotráfico en México encuadra, sin lugar a dudas, en 3 de las 4 definiciones revisadas. Motivo de controversia sería únicamente el criterio relativo al desarrollo de operaciones militares sostenidas, del PA II, instrumento no vigente en México.

Carreón y Téllez ${ }^{94}$ y Arratia, ${ }^{95}$ quienes afirman que no existe un conflicto armado en México, objetan el cumplimiento de los criterios anteriores -incluso el referente a la violencia generalizada-. Dado que ya hemos proporcionado

\footnotetext{
93 Swinarski, art. cit.

94 Carreón y Téllez, art. cit..

95 Arratia, art. cit.
} 


\section{Cuadro 2 \\ Comparativo de elementos de conflictos en México presentes en los instrumentos internacionales de DIH}

\begin{tabular}{|c|c|c|c|c|}
\hline Definición & Articulo $3^{\circ}$ & PA II & Estatuto de Roma & Caso Tadic \\
\hline $\begin{array}{c}\text { Actores } \\
\text { involucrados }\end{array}$ & \begin{tabular}{|c} 
No requiere la \\
participación de las \\
fuerzas armadas \\
del Estado. Es \\
aplicable en \\
conflictos entre \\
grupos armados
\end{tabular} & \begin{tabular}{|c|} 
Se desarrolla entre \\
fuerzas armadas y \\
fuerzas armadas \\
disidentes o grupos \\
armados \\
organizados
\end{tabular} & $\begin{array}{l}\text { No requiere la } \\
\text { participación de las } \\
\text { fuerzas armadas } \\
\text { del Estado. Es } \\
\text { aplicable en } \\
\text { conflictos entre } \\
\text { grupos armados }\end{array}$ & $\begin{array}{l}\text { No requiere la } \\
\text { participación de las } \\
\text { fuerzas armadas } \\
\text { del Estado. Es } \\
\text { aplicable en } \\
\text { conflictos entre } \\
\text { grupos armados }\end{array}$ \\
\hline $\begin{array}{l}\text { Intensidad del } \\
\text { conflicto }\end{array}$ & $\begin{array}{l}\text { Nivel de violencia } \\
\text { propio de un } \\
\text { conflicto armado }\end{array}$ & $\begin{array}{c}\text { Nivel de violencia } \\
\text { propio de un } \\
\text { conflicto armado }\end{array}$ & $\begin{array}{l}\text { Nivel de violencia } \\
\text { propio de un } \\
\text { conflicto armado }\end{array}$ & $\begin{array}{l}\text { Nivel de violencia } \\
\text { propio de un } \\
\text { conflicto armado }\end{array}$ \\
\hline $\begin{array}{l}\text { Organización } \\
\text { de los grupos }\end{array}$ & No lo establece & $\begin{array}{c}\text { Deben estar } \\
\text { organizados bajo la } \\
\text { dirección de un } \\
\text { mando responsable } \\
\text { que pueda dirigir } \\
\text { ataques }\end{array}$ & $\begin{array}{l}\text { Tienen que ser } \\
\text { grupos armados } \\
\text { organizados }\end{array}$ & $\begin{array}{c}\text { Deben ser } \\
\text { organizaciones } \\
\text { armadas }\end{array}$ \\
\hline Control territorial & No lo establece & $\begin{array}{c}\text { Deben ejercer } \\
\text { sobre una parte del } \\
\text { territorio un } \\
\text { control tal..." }\end{array}$ & No lo establece & No lo establece \\
\hline $\begin{array}{c}\text { Operaciones militares } \\
\text { sostenidas y } \\
\text { concertadas }\end{array}$ & No lo establece & $\begin{array}{c}\text { “... que les permita } \\
\text { realizar } \\
\text { operaciones } \\
\text { militares sostenidas } \\
\text { y concertadas" }\end{array}$ & No lo establece & No lo establece \\
\hline $\begin{array}{l}\text { Prolongación del } \\
\text { conflicto }\end{array}$ & No lo establece & No lo establece & $\begin{array}{c}\text { El conflicto } \\
\text { armado debe ser } \\
\text { prolongado }\end{array}$ & No lo establece \\
\hline Ratione Loci & $\begin{array}{c}\text { El conflicto debe } \\
\text { desarrollarse en el } \\
\text { territorio de un } \\
\text { Estado parte }\end{array}$ & $\begin{array}{c}\text { El conflicto debe } \\
\text { desarrollarse en el } \\
\text { territorio de un } \\
\text { Estado parte }\end{array}$ & $\begin{array}{c}\text { El conflicto debe } \\
\text { desarrollarse en el } \\
\text { territorio de un } \\
\text { Estado parte }\end{array}$ & $\begin{array}{c}\text { El conflicto debe } \\
\text { desarrollarse en el } \\
\text { territorio de un } \\
\text { Estado parte }\end{array}$ \\
\hline
\end{tabular}

Se cumple con el requisito $\square$ Se cumple parcialmente con el en el caso de México

$\square$ No se cumple con el requisito en

Fuente: elaboración propia basada en Ferro, 2011; Vité, 2009. 
evidencia empírica para sustentar lo contrario, únicamente nos referiremos a dos objeciones que no han sido abordadas aquí: los objetivos de los narcotraficantes y la posible legitimidad que les otorgaría reconocer el escenario bélico.

Sobre los objetivos, Arratia afirma que "No representan una organización criminal centralizada y en México nunca ha existido indicio alguno de una coalición de narcotraficantes cuyo objetivo sea controlar el Estado, tampoco han tenido ni tienen actualmente la capacidad para lograrlo". ${ }^{96}$

Frente a esta afirmación cabe señalar que las motivaciones de los combatientes no inciden jurídicamente en la tipificación del conflicto. El DIH no regula en función de los objetivos por los cuales actúan los grupos armados (ya sean políticos, controlar el Estado o de cualquier otra índole) sino que norma la conducción de las hostilidades. ${ }^{97} \mathrm{El}$ reconocimiento de un conflicto armado basado en la motivación de los grupos organizados no sólo no es estrictamente jurídico, sino que sería un criterio difícil de aplicar porque, en la práctica, las motivaciones reales de los grupos armados no siempre son discernibles. ${ }^{98}$

Por lo tanto, podemos afirmar como jurídicamente inválidas las objeciones a reconocer la guerra contra el narcotráfico en México como un CANI, debido a la motivación económica del crimen organizado.

Una segunda objeción que plantea Arratia ${ }^{99}$ versa sobre la posible legitimidad que otorgaría a los cárteles el reconocimiento del conflicto armado: "Diagnosticar erróneamente la situación azteca como un conflicto armado no internacional presenta el inconveniente de otorgar legitimidad política implícita a los cárteles, ya que potencialmente éstos serían considerados como 'partes beligerantes' frente al gobierno, convirtiéndolos en un poder de facto". ${ }^{100}$

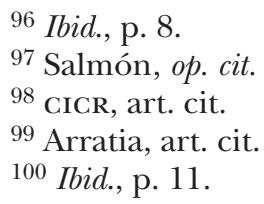


En respuesta al argumento anterior -que no es de índole jurídica, sino política- puede decirse que el artículo $3^{\circ}$ común establece que la aplicación de las disposiciones del DIH no surte efectos sobre el estatuto jurídico de las partes en conflicto. Por lo tanto, el reconocerlos como partes beligerantes no modifica su legitimidad jurídica ni política. Lo que sí hace es hacerlos sujetos de las normas del DIH y proporcionar un marco jurídico que exija un umbral mínimo de humanidad en un contexto altamente deshumanizado.

En consideración de lo anterior, y a manera de balance, se puede afirmar que los datos empíricos sobre el conflicto mexicano cumplen cabalmente con las estipulaciones de tres fuentes diferentes del derecho internacional: el artículo $3^{\circ}$, común a los Convenios de Ginebra (también llamado "convenio miniatura"); el Estatuto de Roma, instrumento máximo de la Corte Penal Internacional y la Jurisprudencia del caso Tadic, la cual sienta las bases para la interpretación de la ley. De reconocerse internacionalmente esta situación, el gobierno mexicano estaría obligado por dichos instrumentos.

Su aplicabilidad podría ser dudosa a la luz del Protocolo Adicional II, aun si este fuera un instrumento vigente en México, fundamentalmente si se considera la existencia de operaciones militares sostenidas como un criterio obligatorio. Esto, sin embargo, más que constituir una razón para desestimar el caso mexicano, debe ser una señal de alarma para la comunidad internacional y los estudiosos del derecho. Si un conflicto de indudable violencia, de evidente colusión de las autoridades y de incuestionable opacidad en el manejo de la información no califica como conflicto armado, es evidente una carencia en el derecho internacional humanitario y la necesidad de solventarla, adecuándose a la realidad y características de formas de guerra contemporánea. 


\section{IMPLICACIONES DEL RECONOCIMIENTO DEL CANI}

En caso de reconocer para México la existencia de un conflicto armado no internacional, las obligaciones aplicables derivadas del artículo $3^{\circ}$ y el Estatuto de Roma, serían las siguientes:

El artículo $3^{\circ}$, entre otras, establece como obligaciones el trato digno y humano a todas las personas que no participen directamente en las hostilidades, incluyendo a quienes hayan depuesto las armas o estén fuera de combate por enfermedad, herida, detención u otra causa. Prohíbe en cualquier tiempo y lugar, al respecto de los mismos, los atentados contra la vida y la integridad corporal (mutilaciones, tratos crueles, tortura y suplicios); la toma de rehenes; los tratos humillantes y degradantes que atenten contra la dignidad personal; las sentencias y ejecuciones sin previo juicio ante un tribunal legítimo, con las garantías judiciales correspondientes. Los heridos y enfermos serán recogidos y asistidos, el CICR podrá ofrecer sus servicios a las partes en conflicto, quienes a su vez harán lo posible por poner en vigor en forma total o parcial las otras disposiciones del Convenio.

El Estatuto de Roma en su artículo $8^{\circ}$ considera crímenes de guerra las violaciones a las garantías enunciadas en el artículo $3^{\circ}$, así como las acciones que dirigen ataques en forma intencional contra la población civil como tal o contra civiles que no participen directamente en las hostilidades; contra edificios religiosos, educativos, de las artes, las ciencias o la beneficencia, los monumentos, los hospitales y otros lugares en que se agrupa a enfermos y heridos, a condición de que no sean objetivos militares. También identifica como crímenes de guerra el saqueo de ciudades o plazas, incluso cuando sean tomadas por asalto; la comisión de actos de violación, esclavitud sexual, prostitución forzada, embarazo forzado o cualquier otra forma de violencia sexual; reclutar o alistar niños menores de 15 años en las fuerzas armadas o grupos o utilizarlos para participar activamente en hostilidades; someter a las personas que estén en poder de otra parte en el conflicto a mutilaciones físicas o a experimentos. 
De acuerdo con Henckaerts, ${ }^{101}$ otros instrumentos jurídicos aplicables a conflictos armados no internos serían el Protocolo sobre Prohibiciones o Restricciones del Empleo de Minas, Armas Trampa y otros Artefactos, posterior a la enmienda del 3 de mayo de 1996; el segundo Protocolo de la Convención de La Haya para la protección de los bienes culturales, que en 1999 se extendió a los conflictos armados no internacionales; el artículo $1^{\circ}$ de la Convención sobre Ciertas Armas Convencionales (CCAC) modificado en 2001 para ampliar el ámbito de aplicación de todos sus protocolos a los conflictos armados no internacionales y, finalmente, la jurisprudencia del Tribunal Especial para Sierra Leona, que consideraba crimen de guerra, con arreglo al derecho internacional consuetudinario, el reclutamiento de niños soldados, incluso en los conflictos armados no internacionales.

Si bien el marco jurídico mexicano en materia de derechos humanos otorga mayores protecciones que las contempladas por el DIH, cabe insistir en la importancia y necesidad de estas últimas, en esencia por tres motivos. En primer lugar, en el contexto de ejecuciones extrajudiciales y de deshumanización de los combatientes resulta imperativo poner límites éticos a la conducción de la guerra. En segundo lugar, significaría una mayor vigilancia internacional a la actuación de las fuerzas armadas mexicanas, lo que podría evitar que se agrave aún más la crisis humanitaria. Finalmente, permitiría llevar a los autores de delitos -ya sean narcotraficantes, miembros del Ejército o autoridades- ante tribunales internacionales. La acusación por la comisión de crímenes de guerra podría tener un peso simbólico y de responsabilidad internacional considerablemente mayor que el de otras formas de sanción por violaciones a derechos humanos.

Con el reconocimiento de conflicto armado para el caso de México, serían exigibles a nivel internacional las protec-

101 J. M. Henckaerts, "Desarrollo del derecho internacional humanitario y la continua pertinencia de la costumbre", Anuario Mexicano de Derecho Internacional, 10, 2010. 
ciones previamente señaladas y su incumplimiento sería justiciable en la Corte Penal Internacional. La desaparición de los 43 estudiantes de Ayotzinapa, por ejemplo, sería susceptible de ser juzgada como crimen de guerra, al igual que las violaciones a derechos humanos a manos del Ejército mexicano; la tortura y reclutamiento de menores por integrantes del crimen organizado; el saqueo a los pueblos y los ataques dirigidos contra la población civil, entre ellos los periodistas. Todos estos escenarios ya ocurren en México, pero en un contexto de impunidad e invisibilidad internacional.

\section{Conclusiones}

A lo largo de este trabajo se ha mostrado que, a pesar de la escasa discusión, el posicionamiento en contra de considerar el conflicto mexicano como un CANI por parte del Estado y de algunos analistas, el conflicto mexicano cumple los criterios para ser tipificado como tal según las estipulaciones de los tres instrumentos más relevantes en esta materia, que han sido ratificados por el país: el artículo $3^{\circ}$, común a los Convenios de Ginebra; el Estatuto de Roma, instrumento máximo de la Corte Penal Internacional y la Jurisprudencia del caso Tadic, que sienta las bases para la interpretación de la ley. Exclusivamente, en el PA II se presenta la discusión en cuanto al criterio de las operaciones militares sostenidas y a una razón ajena al análisis, que es la ratificación de México de este instrumento. La consideración del DIH ofrece elementos relevantes de protección, en tanto que significaría establecer límites éticos a la conducción de la guerra; implicaría mayor escrutinio internacional a la actuación de las fuerzas armadas mexicanas y permitiría llevar a los autores de delitos ante la Corte Penal Internacional.

Entre los temas pendientes que suscita este estudio está la situación de las "nuevas guerras" o conflictos atípicos, donde los combatientes son elementos del crimen organizado 
cuyas motivaciones son económicas y no políticas. Esta clase de conflictos -que, como vimos, no se excluyen a priori como posibles conflictos armados- sí exige que se reconozcan las especificidades y colusiones gubernamentales con las que operan, dado que esto dificulta la posibilidad de fincar responsabilidades.

Ante la contundencia de la evidencia empírica en favor de considerarlo un CANI y las regulaciones que se impondrían, parece hacerse manifiesta una falta de voluntad política por reconocer el carácter del conflicto en México. Y, sin embargo, a la par del no reconocimiento de un escenario bélico, lo que se ha visto en el país ha sido una dependencia cada vez mayor de las fuerzas armadas para contener la violencia. De esta manera, hay un contexto de ambigüedad donde, por un lado, se continúa con el despliegue de unidades militares a lo largo del territorio -como en un escenario de guerra-y, por el otro, no se aplican medidas de DIH ni mecanismos de vigilancia internacional que regulen la conducción de las hostilidades. Si la gravedad de la situación exige el continuo despliegue de las fuerzas armadas, es imperativo que esto ocurra con previo reconocimiento del CANI y la consecuente aplicación de la legislación internacional que vigile y regule el manejo del conflicto.

\section{REFERENCIAS BIBLIOGRÁFICAS}

Alvarado, A. y J. Zaverucha, "La actuación de las fuerzas armadas en la seguridad pública en México y Brasil: una visión comparada”, en Arturo Alvarado y Mónica Serrano (eds.), Seguridad nacional y seguridad interior, México, El Colegio de México, 2010, pp. $228-264$.

Amnistía Internacional, Informe Anual 2016/2017. Desigualdad e impunidad principales obstáculos para los derechos humanos, México, 2017.

Andrade Jardí, J., "Las leyes del narco. La plata, el plomo y San Judas Tadeo", Nexos, 1 de octubre de 1999. 
Appel, M., "Ante el Estado fallido, narcoestado sustituto" Proceso, 8 de mayo de 2012.

Arratia, E., “¿Existe un conflicto armado interno en México según el derecho internacional? Los Convenios de Ginebra y su aplicación en la guerra contra el narcotráfico (2006-2012)", Revista de Estudios en Seguridad Internacional, 2015.

"Aseguran tres campos de entrenamiento del narco en Tamaulipas", Proceso, 29 de julio de 2015.

Atuesta, L. y A. Ponce, Cómo las intervenciones de las fuerzas públicas de seguridad alteran la violencia. Evidencia del caso mexicano, México, Programa de Política de Drogas, cide, 2016.

Bauman, Z., "Wars of the Globalisation Era. European Journal of Social Theory, 4(1), (2001) pp. 11-28, en S. Malešević, The sociology of war and violence, Cambridge, University Press, 2010.

Bauman, Z., "Society under Siege", Cambridge, Polity Press, 2002. En S. Malešević, The sociology of war and violence, Cambridge, University Press, 2010.

Becerril, A., V. Ballinas, C. Gómez y J. A. Román, "Más de 400, los municipios bajo control del narco: legisladores y académicos", La Jornada, 28 de octubre de 2010.

Bellamy, A. J., Guerras justas: de Cicerón a Iraq, Madrid, España, Fondo de Cultura Económica, 2009.

Buscaglia, E., S. González-Ruiz y C. Prieto Palma, "Causas y consecuencias del vínculo entre la delincuencia organizada y la corrupción a altos niveles del Estado: mejores prácticas para su combate", en A. Roemer y E. Buscaglia, Terrorismo y delincuencia organizada. Un enfoque de derecho y economía, Mexico, IIJ/ UNAM, 2006, pp. 87-102

Calle, L. de la, "La ¿interminable? guerra contra el narco en México", CTXT (88), 2016.

Cамасно, Z., "Fuerzas Armadas: más de 4 mil enfrentamientos con el narco", Contralinea, 2017.

"Cárteles mexicanos contratan soldados de Eu como sicarios y capacitadores", La Jornada, 2 de agosto de 2013.

Carreón, H. y E. Téllez, "¿Existe un conflicto armado interno en México? Análisis a la luz del Derecho Penal Internacional”, Lex 2 (10), 2012, pp. 15-42. 
Castillo García, G. "ssp: los cárteles La Línea y La Familia reclutan a mexicanos en penales de EU", La Jornada, 18 de agosto de 2010.

Cedillo, J. A., "Informe revela control de Los Zetas en Coahuila durante los gobiernos de los hermanos Moreira”, Proceso, 6 de noviembre de 2017.

Снават, J., "Seguridad nacional y narcotráfico: Vínculos reales e imaginarios”. Política y gobierno, Vol. 1, núm. 1, (1994), pp. 97-123.

Снават, J., "Narcotráfico y Estado: El discreto encanto de la corrupción”, Letras Libres, 20 de septiembre de 2005.

Comité Internacional de la Cruz Roja, CICR, "El derecho internacional humanitario y los desafíos de los conflictos armados contemporáneos", XXXI Conferencia Internacional de la Cruz Roja y de la Media Luna Roja, Ginebra, 2011.

Comité Internacional de la Cruz Roja, CICR, Los Convenios de Ginebra de 1949 y sus Protocolos adicionales, https://www.icrc. org/es/document/los-convenios-de-ginebra-de-1949-y-susprotocolos-adicionales

Cruz Santiago, C. E., México la guerra invisible. Historias, cifras y negocios de los cárteles criminales y la impunidad de las mafias mexicanas, México, Libera, 2012.

DÁvila, P., "Cae en San Diego, California, fiscal de Nayarit, Édgar Veytia, vinculado al narco”, Proceso, 29 de marzo de 2017.

DíAz, G., "Demanda contra Calderón en La Haya, el 25 de noviembre", Proceso, 2011.

Drug Enforcement Administration, DEA, 2015 National Drug Threat Assessment Summary, U.S. Department of Justice; Drug Enforcement Administration, 2015.

"El 2017 el 'peor' año en inseguridad en la historia reciente: Semáforo Delictivo", Proceso, 24 de octubre de 2017.

Esquivel, J. J., "Cárteles mexicanos, amos del mercado estadounidense de heroína y anfetaminas", Proceso, 14 de diciembre de 2016.

Fernández, J., Las FarC en México: de la política al narcotráfico, México, Editorial Nuevo Siglo/Aguilar, 2008

Ferro, J. J., "Existencia de un conflicto armado interno: ¿quién decide?", Revista de Derecho Público, 2011, pp. 1-31. 
Flores, C., El Estado en crisis: crimen organizado y política. Desafíos para la consolidación democrática, México, Centro de Investigaciones y Estudios Superiores de Antropología Social, 2009.

Flores, C., "La lógica del botín: de la cooptación del Estado y el Estado fallido", en Arenas, 13, 30 (2012), pp. 11-44.

GARzón, J., "El futuro del narcotráfico y los traficantes en América Latina”, en Atlas de la Seguridad y la Defensa de México 2012, México, Colectivo de Análisis de la Seguridad con Democracia A.C. (Casede).

Gil Olmos, J. , "Los nuevos 'esclavos' de los cárteles”, Proceso, 2012. GonzÁlez, F. B., "Necropolítica, de Achille Mbembe”, Clivajes. Revista de Ciencias Sociales, (4), 150, 2015.

Hammer, R. "Cincuenta años de aplicación de los Convenios de Ginebra”, en S. Fraidenraijy R. Méndez Silva (eds.), Elementos de derecho internacional humanitario, México, unAm, Instituto de Investigaciones Jurídicas, 2001.

Henckaerts, J. M., "Desarrollo del derecho internacional humanitario y la continua pertinencia de la costumbre", Anuario Mexicano de Derecho Internacional, 10, 2010.

Henao, D. P., "La lucha armada contra el narcotráfico en Colombia y México: un análisis a la luz del artículo 3 común a los Convenios de Ginebra”, Estudios en Seguridad y Defensa, 8 (16), 2013, pp. 47-58.

Hope, A., "La Guardia Nacional: todos la quieren", El Universal, 15 de mayo de 2019, https:/ /www.eluniversal.com.mx/columna/ alejandro-hope/nacion/la-guardia-nacional-todos-la-quieren

Hurtado, O. y R. García, "El narcotráfico en México como problema transnacional”, Revista mexicana de política exterior, 97, 2013, pp. 35-64.

Institute for Economics and Peace, Índice de paz México 2020, Sídney, 2020, indicedepazmexico.org

International Displacement Monitoring Centre \& Norwegian Refugee Council, Global Overview 2015: People internally displaced by conflict and violence, Ginebra 2015, https:/ / www.internal-displacement.org/publications/global-overview-2015-people-internally-displaced-by-conflict-and-violence 
International Institute for Strategic Studies, IISs, Armed Conflict Survey, IIss, Londres, Routledge, International Institute for Strategic Studies, 2017.

Jaimez, R. y P. Díaz, "Nuevas claves para pensar la violencia en México, más allá del narcocentrismo. Caso Guerrero y su guerra sin fin”, Horizontal, 2017.

Kaldor, M., "New and Old Wars: Organised Violence in a Global Era”, Cambridge, Polity Press, 2001, en Malešević, S., The sociology of war and violence, Cambridge, University Press, 2010.

LAWAND, K., "Conflictos internos u otras situaciones de violencia: ¿cuál es la diferencia para las víctimas?”, Ginebra, Comité Internacional de la Cruz Roja, 10 de diciembre de 2012.

MALEŠEvić, S., The sociology of war and violence, Cambridge, University Press, 2010.

Martínez, F., "Al gobierno le ha faltado organización en la lucha anticrimen, reconoce Blake", La Jornada, 27 de octubre de 2010, https://www.jornada.com.mx/2010/10/27/politica/00 $3 n 1$ pol

México, Presidencia de la República, Plan Nacional de Desarrollo 2019-2024, México, abril de 2019, 64 pp.

Montero, J. C., "La estrategia contra el crimen organizado en México: análisis del diseño de la política pública”, Perfiles Latinoamericanos 20 (39), 2012.

Nájar, A., "Los mapas que muestran los radicales cambios de influencia territorial de los carteles del narcotráfico en México", ввс Mundo, 11 de julio de 2017.

Paullier, J., “¿De dónde salen las armas pesadas del narco en México?”, ввс, 6 de mayo de 2015.

Pérez Correa, C., C. Silva Forné y R. Gutiérrez Rivas, "Índice de letalidad. Menos enfrentamientos, más opacidad", Nexos, 1 de julio de 2015 .

Piaggio, A. y P. Vidwans, The cost and consequences of the war on drugs, Nueva York, Human Rights Foundation, 2019.

"Reporte del inss sobre la violencia en México 'carece de rigor técnico': Segob y SRE” Proceso, 10 de mayo de 2017.

Ríos, V., "How Government Structure Encourages Criminal Violence: The Causes of Mexico's Drug War”, Disertación para 
obtener el grado de Doctor of Philosophy, Cambridge, Harvard University, 2012.

Ríos, V., "To Be or Noт To Be a Drug Trafficker: Modeling Criminal Occupational Choices", Documento de trabajo presentado en la Conferencia Anual del Midwest Political Science Association, 2010.

Rodríguez Fuentes, O. D., "El limbo democrático: Estado de derecho, crimen organizado y paramilitarismo en México", Politai: Revista de Ciencia Política, núm. 11, 2015, pp. 15-32.

Rodríguez, C., Contacto en Italia: el pacto entre los Zetas y la Ndrangueta, México, Debate, 2009.

Roberge, Marie-Claude, "Jurisdicción de los Tribunales ad hoc para ex Yugoslavia y Ruanda por lo que respecta a los crímenes de lesa humanidad y de genocidio”, Revista Internacional de la Cruz Roja, 1997.

Roemer A. y E. Buscaglia, Terrorismo y delincuencia organizada. Un enfoque de derecho y economía, México, unam, Instituto de Investigaciones Jurídicas, 2006, pp. 87-102.

Rosen, J. D. y R. Zepeda, "Una década de narcoviolencia en México: 2006-2016”, en R. Benítez Manaut y S. Aguayo Quezada (eds.), Atlas de la seguridad y la defensa de México 2016 (pp. 5565), México, Senado de la República, Instituto Belisario Domínguez, Colectivo de Análisis de la Seguridad con Democracia, Casede, 2017.

Sánchez Olmos, P., "2019, el año más sangriento de la historia reciente de México”, El Mundo, 24 de diciembre de 2019, https:/ / www.elmundo.es/internacional/2019/12/24/5e00fa 36fdddffff808b4604.html

Saint-Pierre, H. L. y L. M. Donadelli, "El empleo de las fuerzas armadas en asuntos internos", en G. Maihold y S. Jost (eds.), $E l$ narcotráfico y su combate. Sus efectos sobre las relaciones internacionales, México, Konrad Adenauer Stifung, 2014, pp. 59-74.

SALMón, E., Introducción al Derecho Internacional Humanitario, Lima, Instituto de Democracia y Derechos Humanos Pontificia Universidad Católica del Perú, 2004.

Sandoval Ballesteros, N., "México en guerra", Proceso, 2 de febrero de 2012. 
Santamaría, G., "Violencia sin justicia en México: la guerra y sus consecuencias", Open Democracy, 2016.

SAvio, I. "Al servicio del narco: pruebas documentales y testimonios hunden a Yarrington", Proceso, 11 de noviembre de 2017.

SChedler, A., En la niebla de la guerra: Los ciudadanos ante la violencia criminal organizada, México, CIDE, 2015.

Secretaría de Gobernación, Segob, "El reporte 'Armed Conflict Survey 2017' (ACS), publicado por el International Institute for Strategic Studies (IIss)", comunicado de prensa, México, 10 de mayo de 2017.

Serrano, M., "La estrategia de seguridad de Amlo. ¿De la pacificación a la militarización?, Revista IUS, 13 (44), 2019, pp. 207-228.

SHaw, M., "Risk-Transfer Militarism, Small Massacres and the Historic Legitimacy of War. International Relations", 17(3) (2002), pp. 343-60, en Malešević, S., The sociology of war and violence, Cambridge, University Press, 2010.

SHaw, M., "War and Genocide: Organized Killing in Modern Society”, Cambridge, Polity Press, 2003, en S. Malešević, The sociology of war and violence, Cambridge, University Press, 2010.

Sotomayor, G., "Preocupa a ONU 'violencia generalizada' en México", Panorama. Red Internacional de Derechos Humanos, Ginebra, 5 de mayo de 2015 .

Swinarski, C., Introducción al Derecho Internacional Humanitario, Comité Internacional de la Cruz Roja, 1984, https://www.icrc. org/es/doc/resources/documents/misc/5tdl7w.htm

SwinARski, C. S., "Derecho internacional humanitario como sistema de protección de la persona humana en su relación con el derecho internacional de los derechos humanos", en S. Fraidenraij y R. Méndez Silva (eds.), Elementos de derecho internacional humanitario, México, unAm, Instituto de Investigaciones Jurídicas, 2001.

Villaverde, J. C. y J. M. Blanco, "El crimen organizado y la estabilidad estatal en México", I Congreso Internacional de Estudios Militares, Granada, 2014.

ViTé, S., "Tipología de los conflictos armados en el derecho internacional humanitario: conceptos jurídicos y situaciones reales", International Review of the Red Cross, núm. 873, marzo de 2009. 
Voronkova, A., Is Mexico really in a state of conflict?, Londres, IIss Voices, 2017.

Wattenbarger, M., "La búsqueda de respuestas en México", Nacla, 13 de abril de 2020, https:/ / nacla.org/news/2020/04/17/ 5a-brigada-nacional-mexico

US Department of Justice, Drug and Enforcement Administration (DEA), 2015 National Drug Threat Assessment Summary, DEA-DCTDIR-008-16, EEUU, octubre de 2015, https:/ /www.dea.gov/sites/ default/files/2018-07/2015\%20NDTA\%20Report.pdf

\section{Instrumentos jurídicos nacionales e internacionales}

Carta de las Naciones Unidas, 1945.

Convenios de Ginebra del 12 de agosto de 1949.

Estatuto de Roma de la Corte Penal Internacional, 1998.

Protocolo Adicional a los Convenios de Ginebra del 12 de agosto de 1949 relativo a la protección de las víctimas de los conflictos armados sin carácter internacional (Protocolo II), de 8 de junio de 1977.

\section{DECISIONES JUDiCIALES}

Tribunal Penal Internacional para la Antigua Yugoslavia - TPIY, sentencia de 12 de junio de 2002 (Dragoljub Kunarac et al., Appeals Chamber).

Tribunal Especial para la Antigua Yugoslavia. Prosecutor vs. Dusko Tadic a/k/a "dule". Decision on the defense motion for interlocutory appeal on jurisdiction. 